University of Rhode Island

DigitalCommons@URI

Open Access Dissertations

2013

\title{
Alcohol Cognitions and College Student Drinking: The Moderating Effect of Executive Abilities
}

Andrea M. Lavigne

University of Rhode Island, andreamlavigne@gmail.com

Follow this and additional works at: https://digitalcommons.uri.edu/oa_diss

\section{Recommended Citation}

Lavigne, Andrea M., "Alcohol Cognitions and College Student Drinking: The Moderating Effect of Executive Abilities" (2013). Open Access Dissertations. Paper 49.

https://digitalcommons.uri.edu/oa_diss/49

This Dissertation is brought to you for free and open access by DigitalCommons@URI. It has been accepted for inclusion in Open Access Dissertations by an authorized administrator of DigitalCommons@URI. For more information, please contact digitalcommons-group@uri.edu. 
ALCOHOL COGNITIONS AND COLLEGE STUDENT DRINKING:

THE MODERATING EFFECT OF EXECUTIVE ABILITIES

BY

ANDREA M. LAVIGNE

A DISSERTATION SUBMITTED IN PARTIAL FULFILLMENT OF THE

REQUIREMENTS FOR THE DEGREE OF

DOCTOR OF PHILOSOPHY

IN

PSYCHOLOGY

UNIVERSITY OF RHODE ISLAND

2013 


\title{
DOCTOR OF PHILOSOPHY DISSERTATION \\ $\mathrm{OF}$
}

ANDREA M. LAVINGE

\author{
APPROVED: \\ Dissertation Committee: \\ Major Professor Mark Wood, Ph.D. \\ Mark Robbins, Ph.D. \\ Leslie Mahler, Ph.D. \\ Nasser H. Zawia, Ph.D. \\ DEAN OF THE GRADUATE SCHOOL
}

UNIVERSITY OF RHODE ISLAND

2013 


\begin{abstract}
Research informed by dual process models of addictions has clearly demonstrated an association between automatic and controlled alcohol-related cognitions and alcohol use. However, the literature is limited with respect to examination of the cognitive abilities that may moderate these associations across populations. This study examined executive abilities, automatic and controlled alcohol-related cognitions, and alcohol use and problems in sample of college students. It was hypothesized that the executive abilities of working memory and response inhibition would moderate relations between alcohol-related cognitions and involvement. Specifically, it was anticipated that individuals with weaker abilities in these areas would demonstrate stronger relations between automatic cognitions and use, while individuals with stronger abilities in these areas would demonstrate more robust relations between controlled cognitions and use. Research participants completed two Implicit Association Tasks measuring alcohol-related arousal and relaxation associations. In addition, participants completed questionnaires regarding alcohol expectancies, alcohol consumption and problems, and various measures of neuropsychological functioning. We tested study hypotheses using structural equation modeling and probed significant interactions using simple slope analyses. Support for a moderating effect of inhibition abilities on relations between implicit relaxation associations and alcohol involvement was observed. Findings from this study contribute to our understanding of cognitive and neuropsychological factors that contribute to alcohol misuse with important implications for preventive interventions and treatment.
\end{abstract}




\section{ACKNOWLEDGMENTS}

I would like to thank my major professor, Mark Wood, for all of his help and encouragement throughout this work and my time in graduate school. Thank you to the additional members of my dissertation and examination committees, including Mark Robbins, Leslie Mahler, Grant Willis, and Elizabeth Fallon. A sincere thank you to Reinout Wiers and Tim Janssen for their collaboration and for providing the computerized assessments used here.

Thank you to my husband, Chris, for always being there for me and believing in me. We did this together. Thank you to Lorie, my sister and best friend. I don't know what I would do without her. And finally, to Christopher and Katie, the two most precious parts of my life. I'm so lucky to be their mom and they couldn't possibly be more loved. 


\section{PREFACE}

The current document has been prepared in Manuscript Format. Findings from the present study are currently being prepared for submission for publication in Addictions. 


\section{TABLE OF CONTENTS}

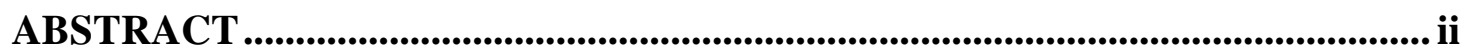

ACKNOWLEDGMENTS ....................................................................................................... iii

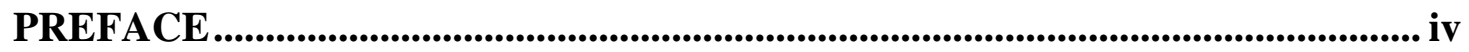

TABLE OF CONTENTS........................................................................................................... v

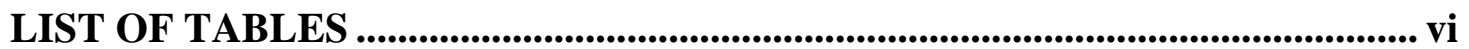

LIST OF FIGURES .................................................................................... vii

CHAPTER 1 ................................................................................................................................. 1

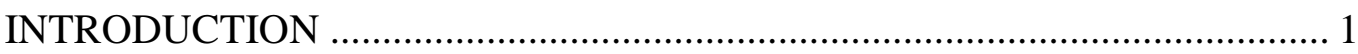

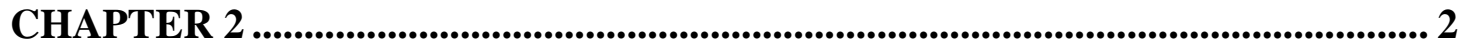

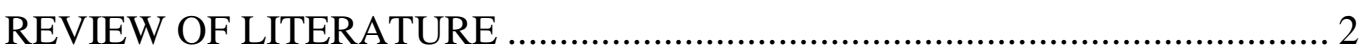

CHAPTER 3 ........................................................................................................................ 17

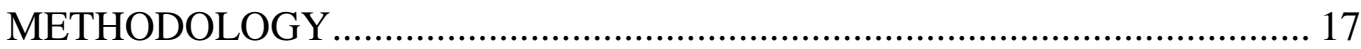

CHAPTER 4 ............................................................................................................................. 28

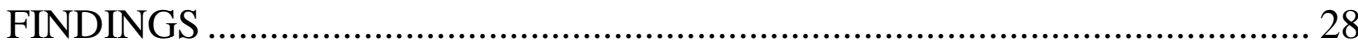

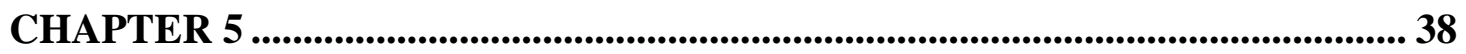

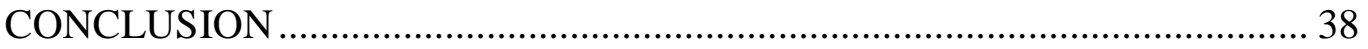

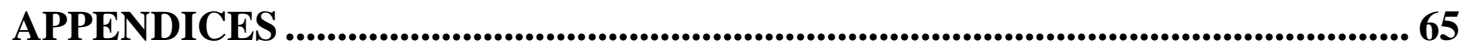

BIBLIOGRAPHY …............................................................................................................... 95 


\section{LIST OF TABLES}

TABLE

PAGE

Table 1. Pearson Product Moment Correlations Among Predictor and Outcome

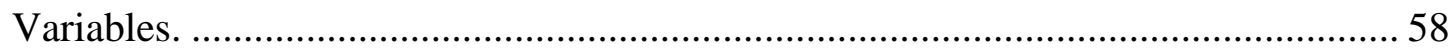

Table 2. Sample Characteristics Across Studies..................................................... 59 


\section{LIST OF FIGURES}

FIGURE

PAGE

Figure 1. Model 1: Arousal Working Memory Structural Equation Model. ............. 60

Figure 2. Model 2: Arousal Inhibition Structural Equation Model.......................... 61

Figure 3. Model 3: Relaxation Working Memory Structural Equation Model.......... 62

Figure 4. Model 4: Relaxation Inhibition Structural Equation Model ..................... 63

Figure 5. Model 5: Implicit Relaxation Associations and Inhibition .......................6 64 


\section{CHAPTER 1}

\section{"Alcohol cognitions and college student drinking: The moderating effect of executive abilities"}

by

Andrea M. Lavigne ${ }^{1}$; Mark D. Wood ${ }^{2}$; Tim Janssen ${ }^{3}$; Reinout W. Wiers ${ }^{3}$

is in preparation for submission to Addictions

${ }^{1} \mathrm{PhD}$ Candidate, Department of Psychology, The University of Rhode Island, Kingston, RI, 02881. Email: andreamlavigne@gmail.com

${ }^{2}$ Professor, Department of Psychology, The University of Rhode Island, Kingston, RI, 02881. Email: mark_wood@uri.edu

${ }^{3} \mathrm{PhD}$ Candidate, Department of Psychology, University of Amsterdam, Amsterdam, the Netherlands. Email: t.janssen@uva.nl

${ }^{3}$ Professor, Department of Psychology, University of Amsterdam, Amsterdam, the Netherlands. Email: r.w.wiers@gmail.com 


\section{CHAPTER 2}

\section{REVIEW OF LITERATURE}

Heavy drinking and alcohol-related negative consequences continue to be a significant public health issue among college students in the United States. The range of negative outcomes resulting from alcohol misuse is great, spanning problems in academic performance, health, safety, driving while intoxicated, unintended injury, sexual assault, and death (Hingson, Zha, \& Weitzman, 2009; Perkins, 2002). Given its prevalence, a great deal of research has been conducted to increase our understanding of alcohol misuse, with much attention given to the cognitive processes involved. In early and influential work in cognitive psychology, Shiffrin and Schneider (1977) broadly differentiated cognitive processes as automatic or controlled. Automatic processes were described as those not requiring attention and as relatively difficult to change, whereas controlled processes require deliberate attention and are purportedly easier to modify (1977). By studying these cognitive processes, alcohol researchers are able to elucidate the implicit associations and explicit cognitions individuals hold in memory and investigate their unique relations with measures of alcohol involvement, as reviewed next.

\section{Explicit Alcohol-Related Cognitions and Alcohol Involvement}

Within the realm of controlled processes are explicit alcohol-related cognitions, herein referred to as alcohol expectancies. Alcohol expectancies are "anticipated effects of drinking alcohol" (Wiers \& Stacy, 2010, p. 13) and influence both the initiation and maintenance of alcohol use (Leigh, 1989). Several different types of alcohol expectancies have been found to exist, including positive 
reinforcement expectancies (e.g. alcohol increases sociability), negative reinforcement expectancies (e.g. alcohol reduces tension), and negative expectancies (e.g., alcohol negatively affects academic performance) (Fromme, Stroot, \& Kaplan, 1993; Wiers, Houben, Smulders, Conrod, \& Jones, 2006). In a review of this literature, Goldman, Del Boca, \& Darkes (1999) concluded that expectancies have consistently been found to be associated with quantity and frequency of use and alcohol-related problems. Additionally, in prospective research, expectancies and alcohol use have been shown to influence one another reciprocally (Sher, Wood, Wood, \& Raskin, 1996; Smith et al., 1995). Although the assessment of expectancies in adolescence has been shown to predict current (see Goldman et al., 1999; Leigh \& Stacy, 1993) and prospective (Sher et al., 1996; Stacy 1997) alcohol use, even decades later into middle adulthood (Patrick, Wray-Lake, Finlay, \& Maggs, 2010), it is clear that expectancies are best viewed as important components of more complex cognitive or psychosocial models. As dual process models of cognition have gained prominence in psychology (e.g., Strack \& Deutsch, 2004), alcohol researchers have increasingly studied the relatively automatic cognitive processes that contribute to alcohol misuse.

\section{Implicit Alcohol-Related Associations and Alcohol Involvement}

Implicit associations are relatively automatic associations formed over time that are "triggered in the impulsive system from the activation of associative clusters in long-term memory" when individuals encounter stimuli, such as passing a bar (Hofmann, Friese, \& Wiers, 2009, p.5). While both implicit associations and expectancies have been shown to predict alcohol use, several methodological benefits to using implicit or indirect measures have been proposed. Most notably, implicit 
measures do not require conscious awareness and bias from social desirability responding is removed (Banaji \& Heiphetz, 2010; Greenwald, McGhee, Schwartz, 1998; Stacy \& Wiers, 2010; Wiers et al., 2007).

Among the most commonly utilized tools in the assessment of implicit associations is the implicit association task (IAT; Greenwald et al. 1998; Greenwald, Poehlman, Uhlmann, \& Banaji, 2009). The IAT is a computerized test of reaction time in which participants are asked to categorize target and non-target stimuli (e.g., pictures or words relating to alcoholic drinks) as quickly as possible. The rationale behind the IAT is that response times are faster when participants are asked to categorize stimuli in ways compatible with their implicit views. In a review of more than 100 studies that utilized the IAT, Greenwald et al. (2009) report average effect sizes within the moderate range and incremental predictive utility when employed in addition to explicit measures across a variety of attitudes and behaviors, particularly with respect to socially sensitive attitudes (e.g., evaluation of stimuli association with ethnic minorities; Greenwald et al., 1998).

Researchers began studying implicit alcohol associations based on the notion that these associations will influence decisions surrounding use when they are activated or triggered by cues in the environment (Stacy, Ames, Sussman, \& Dent, 1996). Findings across studies in this area have consistently demonstrated the utility of assessing implicit associations in the study of alcohol involvement (Houben \& Wiers, 2006; Jajodia \& Earleywine, 2003; Palfai \& Wood, 2001; Stacy et al., 1996; Thush \& Wiers, 2007; Wiers, van Woerden, Smulders, \& de Jong, 2002). Specifically, positive and arousing implicit associations appear to be most strongly 
associated with use, while generally negative or sedating implicit associations are not (Houben \& Wiers, 2009; Jajodia \& Earleywine, 2003; Leigh \& Stacy, 1998; Thush \& Wiers, 2007; Wiers et al., 2002), although see Houben and Wiers (2006).

Initial support for the hypothesis that implicit (e.g., automatic) alcohol-related associations serve as important predictors of alcohol involvement was found when these associations were compared between a total of 48 heavy and light drinking Dutch college students in terms of valence and arousal (Wiers, Woerden, Smulders, \& de Jong, 2002). Specifically, findings revealed stronger arousal implicit associations and expectancies in heavy drinkers compared to light drinkers, while both groups possessed strong implicit negative associations. Additionally, results of implicit association tasks contributed significant unique prediction to drinking one-month later, after variables such as sex and expectancies were controlled. In a comparison of abstaining and drinking Dutch high school students, Thush and Wiers (2007) found heavier drinking to be associated with stronger positive implicit associations, positive expectancies, and arousal expectancies. In addition, implicit associations significantly added to the prediction of alcohol use one year later.

Jajodia and Earleywine (2003) assessed implicit positive and negative alcohol associations in 115 American college students with and without drinking experience. Alcohol use in the past 30 days was assessed using the Timeline Follow-back method (Sobell \& Sobell, 1995). Results of multiple hierarchical regression analyses revealed positive implicit associations were associated with each of the three alcohol use variables measured (e.g., quantity of use in the past 30 days, frequency of drinking episodes in the past 30 days, and maximum number of drinks consumed on a single 
day in the past 30 days). These relations were evident after controlling for the variance explained by expectancy measures and background variables. In contrast, negative associations were not related to drinking outcomes, and alcohol-related problems over the past three years were not associated with either of the positive or negative implicit measures.

In additional research employing IAT approach, Houben and Wiers (2006) studied alcohol-related associations in 96 Dutch college student drinkers. Alcohol use was again assessed using the Timeline Follow-back method in which participants were asked to report the amount of alcohol they consumed each day for the past week. These researchers used IATs to measure implicit arousal and sedating associations. Multiple hierarchical regression analyses revealed implicit arousal associations were significantly associated with past-week alcohol use when other variables, including sex and expectancies, were taken into account. In this study, implicit positive associations approached significance. Of the various implicit scores obtained, only implicit sedation associations significantly related to alcohol problems. Additionally, implicit negative associations did not differentiate among different levels of drinking. These findings are similar to previous findings in this area (Jajodia \& Earleywine, 2003) and support the measurement of implicit associations in addition to expectancies. The importance of assessing arousal expectancies was illustrated as both arousal implicit associations and arousal expectancies were related to current use, while sedation implicit associations were associated with current alcohol problems.

In other work using word association tasks as measures of implicit associations, Stacy and others (1996) assessed implicit cue- and outcome-behavior 
associations so the predictive utility of implicit alcohol and marijuana associations could be determined. In this study, the researchers instructed 143 American alternative high school students (41.6\% Hispanic) to write the first word they thought of next to a variety of printed words, some of which were alcohol or marijuana cues (ex. draft, pot) and some that were neutral (ex. pupil). The researchers also assessed outcome-behavior associations by asking participants to list a behavior that they associated with particular states, such as being relaxed and sociable. Combined, these measures of implicit substance-related cognitions significantly related to past alcohol use in this adolescent sample. Additional work by Stacy (1997) showed implicit alcohol-related memory associations in 342 predominately Asian-American college students, again measured by cue- and outcome-behavior associations, were predictive of prospective alcohol use (one-month later) even after controlling for past use.

In their examination of implicit alcohol associations and expectancies in 314 college students, Palfai and Wood (2001) utilized a word association task which had been used in previous research (Stacy, 1997) to measure positive implicit associations. In this task, individuals were presented with a list of phrases that indicated positive outcomes (e.g., "feeling relaxed") and were instructed to write down the two behaviors they immediately associated with the outcomes. Responses were coded to indicate whether participants associated alcohol with the positive outcomes. These researchers found positive implicit associations and positive expectancies significantly related to past-year alcohol involvement in terms of frequency and quantity of use, heavy use, and alcohol problems, when sex was controlled. Further, exploration of an interaction effect between implicit associations and expectancies indicated that positive implicit 
associations moderated the relationship between expectancies and frequency of alcohol use. Specifically, expectancies were more strongly associated with use for individuals with stronger positive implicit associations.

Support for the utility of assessing implicit alcohol associations was further provided by Lindgren and others, who in 2012 administered several different alcoholrelated IATs to undergraduate college students. The range of alcohol associations measured included approach-avoidance, excitement, cope, stress drinking, drinking identity, and a control IAT which measured associations between alcohol and theoretically unrelated stimuli. Results showed the IAT to be a valid measure of implicit alcohol associations with drinking identity, alcohol excitement, and alcohol approach showing stronger relations with drinking levels after expectancies were accounted for (2012).

\section{Integrating Implicit and Explicit Cognitive Processes: Toward A Dual Process}

\section{Approach}

Collectively, findings provide support for the utility of assessing both implicit associations and expectancies given observed cross-sectional and prospective relations with alcohol and other drug outcomes (see also Wiers \& Stacy, 2010). While these processes do not necessarily conflict, Houben and Wiers state "the more implicit impulsive system and the more explicit reflective system trigger simultaneous, conflicting signals, but ultimately, behavioral decisions are determined by the relative strengths of impulsive and reflective processes, so that stronger processes gain advantage over weaker ones" (2009, p. 626). One model that can accommodate the joint contribution of implicit associations and expectancies on behavior such as 
alcohol involvement is the dual process approach (Strack \& Deutsch, 2004; see also Wiers et al., 2010). Although a comprehensive examination of the numerous components of the dual process model is beyond the scope of this study (see Wiers et al. 2007), the integration of implicit and explicit processes herein, with consideration of the influence of executive functions, is consistent with the major tenet of the model. Thus, the dual process model of addictions serves as a guide for the current study.

\section{Neuropsychological Functioning: Executive Functioning and the Dual Process}

\section{Model}

Executive functioning refers to a group of higher-order abilities mediated by the prefrontal lobe that are integral to behavior regulation, including attention, planning, abstraction, cognitive flexibility, working memory, and inhibition (Crews \& Boettiger, 2009; Giancola \& Tarter, 1999). Consistent with the dual process approach, a number of recent studies have examined the moderating role of executive functions for relations between implicit associations and expectancies and a number dependent variables, such as alcohol use (Grenard et al., 2008; Hofmann, Gshwendner, Friese, Wiers, \& Schmitt, 2008; Houben \& Wiers, 2009; Thush et al., 2008; Wiers, Beckers, Houben, \& Hofmann, 2009). As noted by Wiers and Stacy (2010) and detailed subsequently, across multiple measures of executive functioning and with implicit associations measured via "first word associations" and IAT approaches, support for a moderating role of executive functioning has been observed. The current study will consider performance in multiple areas of executive functioning with specific attention given to working memory and inhibition abilities, as these executive abilities are particularly relevant to decisions surrounding alcohol use (Crews \& Boettiger, 2009). 
Working memory. Mediated by the dorsolateral prefrontal cortex, working memory abilities "hold information in an activated state for a short period of time...in order to make it available for further processing, manipulation and updating by higher cognitive processes" (Piechatzek et al., 2009, p. 651). Working memory has been described as the executive ability of directing attention among distracting information (Engle, 2002). In the context of the dual process approach to understanding health behaviors, it follows that working memory abilities would impact one's ability to use effortful processing in the presence of various cues, such as those involving alcohol (Hofmann et al., 2009), As detailed subsequently, recent research consistent with the dual process model has examined the influence of executive abilities on relations between alcohol cognitions and alcohol involvement, with specific attention given to the domain of working memory abilities. Findings from this research provide important initial support for the dual process model of addiction in that working memory ability, an important executive ability has been shown to moderate relations between alcohol cognitions on alcohol involvement.

For example, in their work exploring the moderating role of working memory abilities on implicit alcohol associations, Grenard and others (2008) studied relations among working memory ability, drug associations, and substance use in 145 predominately Latino (69.7\%) alternative high school students in the United States. These researchers utilized the Subject-Ordered Pointing Task (Petrides \& Milner, 1982) to assess working memory and assessed implicit associations with various word association tasks. Consistent with their hypotheses, they found that individuals with low working memory abilities demonstrated stronger relations between implicit 
substance-related associations and substance involvement, namely, alcohol and tobacco, than those with higher working memory abilities. These researchers did not assess expectancies, and as noted previously, only included students from an alternative high school. These characteristics of the study limit our understanding of the moderating role of working memory ability on alcohol expectancies as well as our ability to generalize the findings to other, higher-functioning populations.

In additional work examining the influence of working memory abilities in conjunction with implicit and explicit cognitive processes, Thush et al. (2008) examined working memory ability and alcohol associations and expectancies as predictors of alcohol involvement in a sample of 88 young Dutch adolescent vocational school students. These participants were, on average, 16 years of age (SD $=1.3$ ). These researchers assessed implicit alcohol associations using three unipolar IATs (positive reinforcement vs. neutral, negative reinforcement vs. neutral, and negative associations vs. neutral) and assessed expectancies with a questionnaire derived directly from their IATs. Additionally, participants were given the SubjectOrdered Pointing Task as a measure of working memory ability. Three hierarchical regression models were examined (one each for positive reinforcement, negative reinforcement, and negative associations). Their model on positive reinforcement associations (i.e., positive arousal) approached significance. Follow-up analyses showed a significant interaction effect between working memory abilities and arousal associations without the presence of main effects. Specifically, positive reinforcement (e.g. arousal) associations predicted prospective alcohol involvement one month later for individuals with low working memory abilities, while individuals with higher 
working memory abilities showed stronger relations between arousal expectancies and prospective drinking. Additionally, positive reinforcement (e.g. arousal) expectancies were more predictive of alcohol involvement for individuals with high working memory abilities. These findings are consistent with a dual process model as they suggest that individuals with high working memory abilities utilized more explicit cognitive deliberation for drinking behavior, while those with low working memory abilities were influenced more by implicit or automatic processes.

Inhibition. In addition to working memory abilities, another executive function that has received some recent attention in the dual process literature is inhibition. In terms of human behavior, inhibition abilities mitigate impulsivity, a pattern of responding to environmental stimuli defined as "an inability to wait, a tendency to act without forethought, insensitivity to consequences, and an inability to inhibit inappropriate behaviors" (Reynolds, Ortengren, Richards, \& de Wit, 2006, p. 306; see also Crews \& Boettiger, 2009; Dick et al. 2010; Dougherty, Mathias, Marsh, \& Jagar, 2005; Lawrence, Luty, Bogdan, Sahakian, \& Clark, 2009). The present study will focus on laboratory-based measures of impulsivity, which unlike questionnairebased measures, do not require self-awareness (Reynolds et al. 2006). Specifically, the current study will focus on pre-potent response inhibition, which is the "ability to inhibit an already initiated response" (Dougherty et al., 2005 p. 83) and is hypothesized as especially relevant to counteracting the influence of automatic processes (Houben \& Wiers, 2009). To date, research on the moderating effect of response inhibition on implicit alcohol associations in college students is limited to a single study which took place in the Netherlands (Houben \& Wiers, 2009). These 
researchers conducted hierarchical multiple regression analyses with a summary score of alcohol use and related problems as the dependent variable. Implicit arousal and positive alcohol associations were assessed using IATs, and response inhibition (e.g., the ability to inhibit or stop a response) was measured with the Stroop test. Significant interaction effects between the arousal IAT and positive IAT with Stroop scores were observed. These scores were probed with simple slope analyses to reveal that, again consistent with a dual process approach, strong inhibition abilities moderated the effect of implicit alcohol associations. Specifically, individuals with higher inhibition abilities did not demonstrate significant relations between positive and arousal implicit associations and alcohol involvement. However, individuals with lower inhibition abilities demonstrated significant relations between these implicit associations and alcohol involvement.

As noted, these and prior findings provide promising initial support for dual process cognitive models of alcohol use. However, they are limited in terms of lack of replication and extension to other populations. For example, in the area of working memory abilities, the two studies to date have been conducted with small samples of U.S. and Dutch adolescents (Grenard et al., 2008; Thush et al., 2008). In regards to the moderating effect of inhibition abilities on implicit associations, to our knowledge, only one study has been conducted which used a Dutch sample and did not include the assessment of alcohol expectancies. Accordingly, with the current study, we sought to replicate and extend existing research findings in the area of executive functioning, implicit and explicit alcohol cognitions, and alcohol involvement. We extended previous work to determine whether findings in this area generalize to a sample of 
American college students, a population known to be at risk for alcohol-related problems (Hingson et al., 2009; Perkins, 2002). With this study we also assessed multiple measures of executive functioning, allowing for greater delineation of the executive abilities that serve as moderators. In addition, this study was the first study to our knowledge to examine relations between inhibition abilities and alcohol expectancies.

\section{Major Hypotheses}

Hypothesis 1A: Working memory and implicit arousal associations. We hypothesized that working memory abilities would moderate relations between implicit arousal associations and alcohol involvement. It was expected that the nature of this relationship would be such that individuals with strong working memory abilities would show weaker relations between arousal implicit associations and alcohol involvement.

\section{Hypothesis 1B: Working memory and explicit arousal expectancies. We} hypothesized that working memory abilities would moderate relations between arousal expectancies and alcohol involvement. Specifically, it was hypothesized that individuals who possessed strong working memory abilities would exhibit stronger relations between arousal expectancies and alcohol involvement.

\section{Hypothesis 2A: Inhibition and implicit arousal associations. It was}

hypothesized that inhibition ability would moderate relations between arousal implicit associations and alcohol involvement such that individuals with strong inhibition abilities would show weaker relations between arousal implicit associations and alcohol involvement. 


\section{Hypothesis 2B: Inhibition and explicit arousal expectancies. The}

moderating role of inhibition on arousal expectancies was also investigated. It was hypothesized that individuals with strong inhibition abilities would display stronger relations between arousal expectancies and alcohol involvement, as strong inhibition abilities would allow these individuals greater opportunities to utilize deliberate, conscious reasons for using alcohol.

\section{Hypothesis 3A: Working memory and implicit relaxation associations.}

We hypothesized that working memory abilities would moderate relations between implicit relaxation associations and alcohol involvement. The nature of this relationship was expected to be such that individuals with strong working memory abilities would show weaker relations between relaxation implicit associations and alcohol involvement.

\section{Hypothesis 3B: Working memory and explicit relaxation expectancies.} We hypothesized that that working memory abilities would moderate relations between relaxation expectancies and alcohol involvement, such that individuals with strong working memory abilities would show stronger relations between relaxation expectancies and alcohol involvement.

Hypothesis 4A: Inhibition and implicit relaxation associations. It was hypothesized that inhibition abilities would moderate relations between relaxation implicit associations and alcohol involvement, such that individuals with strong inhibition abilities would show weaker relations between relaxation implicit associations and alcohol involvement. 
Hypothesis 4B: Inhibition and explicit relaxation expectancies. It was hypothesized that individuals with strong inhibition abilities would display stronger relations between relaxation expectancies and alcohol involvement, as strong inhibition abilities would allow these individuals greater opportunities to utilize deliberate, conscious reasons for using alcohol. 


\section{CHAPTER 3}

\section{METHODOLOGY}

\section{Sample and Recruitment}

Data were collected from 273 participants during the spring and fall semesters of 2011. Three participants were removed from analyses because they did not meet age inclusion criteria $(18-25)$, did not provide their age, or failed to complete all assessments. Sixteen participants indicated that they had never consumed alcohol and were excluded. Of the remaining 254 individuals, 36 reported having a formal diagnosis of Attention Deficit Hyperactivity Disorder and were excluded. In the remaining sample of 218 participants, 13 reported a history of head injury that resulted in loss of consciousness for at least 15 minutes and were excluded from analysis, resulting in a final sample of 205 participants. The final sample was on average 19.0 years old $(S D=1.1)$ and were mostly female $(n=150,73.2 \%)$. The majority of participants were freshmen $(n=113,55.1 \%)$, followed by sophomores $(n=36$, $17.6 \%)$, juniors $(n=34,16.6 \%)$ and seniors $(n=22,10.7 \%)$. Most participants were white $(n=162,79.8 \%)$, followed by other $(n=16,7.9 \%)$, more than one/mixed $(n=$ 12, 5.9\%), black ( $n=9,4.4 \%)$, and Asian $(n=4,2.0 \%)$. Two participants did not indicate their race. There were 28 (13.7\%) Hispanic/Latino participants. There was a greater percentage of female and Hispanic students in our sample compared to the URI student body in the fall of 2010, which comprised $54.8 \%$ female and $6.4 \%$ Hispanic/Latino undergraduate students. 
Students were first informed of the opportunity to participate with a verbal inclass announcement when they were invited to participate in a study on college student health behaviors. The focus on alcohol-related cognitions and behaviors was not announced during this initial invitation in order to minimize sampling bias. However, the focus on alcohol cognitions and involvement was reviewed in the consent process so informed consent could be obtained. After receiving permission from class instructors and teaching assistants, project staff attended numerous lectures and recitations, describing the study and passing around a sign-up sheet. Interested students were invited to reserve a one-time, 60-minute appointment with a member of the research team to complete study-related assessments. Course instructors offered extra class credit for participation. As an additional incentive for participation, we applied for and were awarded an Enhancement of Graduate Research and Awards Grant of $\$ 1,000$ so we could offer participants a chance to win one of 100 gift cards valued at $\$ 10$ to purchase music. The day before each appointment, study staff sent each participant a reminder phone call and email.

\section{Procedure}

Participants first provided informed consent (Appendix A). Signed consent forms were stored separately from study-related data and all results remained anonymous. Prompts for participants to put forth their best effort and for staff to check for missing data were used to minimize the amount of missing or invalid data (Appendix B). After signing the consent form, participants completed three neuropsychological tests of executive abilities (e.g., Letter-Number Sequencing Task, Subject-Ordered Pointing Task, and Stroop Test). The order of administration of these 
tests were randomized using an on-line randomization program

(http://www.randomizer.org/). Participants then completed arousal and relaxation implicit association tasks in counterbalanced order. We then administered a questionnaire assessing alcohol expectancies. Next, participants completed assessments regarding their alcohol use for the previous 30 days and experience of alcohol-related problems over the previous year. Finally, participants provided demographic information. Upon completion of these assessments, participants were debriefed (Appendix C) and their questions answered. In addition, participants were given the opportunity to be entered into a drawing for one of 100 iTunes gift cards valued at $\$ 10$ each that could be used to purchase music. The total time required for completion of assessments was approximately 50 minutes. At the end of each semester, a partial drawing was conducted for the gift cards and winners were informed by telephone or e-mail of how they could pick up their gift cards. In addition to the primary investigator, assistance with data collection was provided by a total of ten undergraduate research assistants (four in the spring semester and six in the fall semester) who received research experience in exchange for course credit. Prior to beginning work on the study, all individuals completed a certification course on research with human subjects through the Institutional Review Board. The first several weeks of each semester were devoted to training and practicing standardized administration of measures and study-related procedures. Individual and group supervision was provided throughout the semester. 


\section{Measures}

Demographics. Participants provided demographic information on age, sex, race, ethnicity, class, GPA, and residential status (Appendix D1). Family history of alcohol problems and level of education obtained by each parent were assessed as were history of treatment for alcohol-related problems, traumatic brain injury with loss of consciousness lasting 15 minutes or longer, and any formal diagnosis of ADD/ADHD.

Alcohol use. Alcohol use was assessed with Timeline Follow-back method, considered the most reliable and valid approaches for assessing alcohol consumption (Sobell \& Sobell, 1995; Sobell, Sobell, Klajner, Pavan \& Basian, 1986). Participants were asked to indicate the number of drinks they consumed each day for the past 30 days using a calendar format (Appendix D2). Three indicators of alcohol use were derived, including average weekly number of drinks, number of gender-specific heavy drinking episodes in the previous 30 days (defined as 5 or more drinks on one occasion for a male, and 4 of more drinks on one occasion for a female), and maximum number of drinks on one occasion during the previous 30 days. Assessing alcohol use with the Timeline Follow-back with college students across the spectrum of drinking levels has proven reliable, with test-retest reliability values ranging from .70 to .96 across the different categories of drinking levels (e.g., abstinent, light, moderate, and heavy drinking days; Sobell et al., 1986).

Alcohol problems. Alcohol-related problems were assessed using the Brief Young Adult Alcohol Consequences Questionnaire (Appendix D3; B-YAACQ; Kahler, Strong, \& Read, 2005). The B-YAACQ is a 24-item questionnaire with a 
dichotomous response format that assesses the broad range of alcohol-related problems experienced by college students in the previous year. A sample item is "I have passed out from drinking." Response options were coded so that $0=$ "no" and 1 $=$ "yes." The B-YAACQ was previously shown to be highly correlated with the original YAACQ $(r=.95)$ with an internal consistency value of alpha $=.83$ (Kahler et al., 2005). The YAACQ, in turn, has previously demonstrated concurrent validity values ranging from $r=.68$ to $r=.85$ with test-retest reliability (time interval of 1 week) of .86 (Read, Merrill, Kahler, \& Strong, 2007). A single score was calculated by summing responses across all items with higher values indicating greater problems. Coefficient alpha for our sample was .82.

Implicit alcohol associations. Participants completed two IATs. The first IAT (hereafter referred to as the arousal IAT) was in a bipolar format to assess positive/arousal vs. negative/sedation implicit associations. Participants also completed a unipolar IAT to assess positive/sedating implicit associations with alcohol (herein referred to as the relaxation IAT). In a review of the psychometric properties of IATs, Schnabel, Asendorpf, \& Greenwald (2008) report an average internal consistency reliability value of .70 to .90 , with an average test-retest reliability value of .56. Previous findings support the presence of discriminant validity with relatively low correlation between IATs and corresponding explicit measures ( $r s=.24$ and .37$)$. Results of recent research comparing several alcohol IATs within a single study, including a control IAT in which alcohol stimuli was categorized along with stimuli unrelated to drinking, provided evidence for convergent and discriminant validity of the IAT in alcohol research (Lindgren et al., 2012). 
Selection of IAT stimuli. Words selected for the arousal and relaxation IATs were based on previous research (Fromme, et al., 1993; Houben, Nosek, \& Wiers, 2010; Kushner, Sher, Wood, \& Wood, 1994; Martin, Earleywine, Musty, Perrine, \& Swift, 1993; Rather, Goldman, Roehrich, \& Brannick, 1992; Thush et al., 2008) and chosen in consultation with other researchers (R.W. Wiers \& T. Janssen, personal communication, March 6, 2011). In addition, we conducted pilot testing of potential words for the implicit tasks by obtaining word ratings from 25 undergraduate students. We presented these individuals with 44 words (see Appendix E) and asked them to rate their positive or negative associations with each word. We also asked these individuals to rate their sedating or arousing associations with each word. We instructed individuals to "Please read and rate each word carefully but quickly, not spending too much time on any single word. If you are unsure of the meaning of any word, please place a question mark next to the word and move on to the next word." Based on the results of these word ratings and review of stimuli used in previous research, we selected talkative, funny, happy, excited, confident, and brave to serve as the positive/arousing stimuli for the arousal IAT. Negative/sedating stimuli for the arousal IAT included withdrawn, miserable, sad, depressed, sick, and down. Positive/sedating stimuli for the relaxation IAT included relaxed, calm, peaceful, tranquil, carefree, and comfortable. Neutral stimuli for the relaxation IAT included average, normal, general, ordinary, typical, and usual. Alcohol stimuli included beer, wine, liquor, vodka, tequila, and rum, whereas non-alcohol stimuli were soda, water, milk, coffee, tea, and Gatorade. 
The format of the IATs was identical to those used in related research (Houben \& Wiers, 2009). Each IAT consisted of seven blocks and took approximately 5 minutes to complete. For the arousal IAT, the first three blocks were practice blocks. During the first practice block, participants were asked to categorize alcohol and nonalcohol words. A word representing the target stimuli (e.g., beer, Gatorade) appeared at the center of the screen, with the label "Alcohol" appearing on the top left of the screen and the word "Not Alcohol" appearing on the top right. Participants were instructed to press the "Q" key if the word that appeared in the center of the screen belonged to the category on the left, and to press the "P" key if the word belonged to the category on the right. During the second practice block, participants were asked to categorize attribute words (e.g., talkative, withdrawn). Here, the label on the top left of the screen was "Arousal" while the label on the top right of the screen was "Sedation." During the third practice block, target and attribute labels were combined such that "Alcohol or Arousal" appeared on the top left of the screen, while "Not Alcohol or Sedation" appeared on the top right of the screen. Participants were presented with words representing alcohol and non-alcohol stimuli, as well as arousing and sedating words, and asked to press the "Q" key if the word belonged to either the Alcohol or Arousal categories. Similarly, they were asked to press the "P" key if the word belonged to either the Not Alcohol or Sedation categories. The fourth block comprised 48 trials and was the first test block. The format of this block was the same as the third block. The fifth block was a practice block similar to the first block, except here the location of the target categories was reversed. For example, if the participant was previously presented with "Alcohol" on the top left of the screen and 
"Not Alcohol" on the top right of the screen, these locations would be reversed. The sixth block was also a practice block in which the target and attribute categories were once again combined, and participants were asked to categorize words that appeared in the center of the screen. For example, "Not Alcohol or Arousal" would appear on the top left of the screen, and "Alcohol or Sedation" would appear on the top right of the screen. Participants were instructed to press the "Q" key if the word belonged to either the Not Alcohol or Arousal categories, or to press the "P" key if the word belonged to either the Alcohol or Sedation categories. The seventh and final block was a test block constructed in the same way as block six. Each practice block consisted of 24 trials while the two test blocks consisted of 48 trials each. Errors resulted in a red " $\mathrm{X}$ " appearing in the center of the screen, with a two-second delay before the trial was repeated. The location of the targets was counterbalanced to correct any left or right preference.

The D-score derived from the IAT is a measure of the difference in response times between the compatible and incompatible combinations, such that higher scores indicate faster reaction times for alcohol/arousal and not alcohol/sedating combinations, compared to alcohol/sedating and not alcohol/arousing combinations. The procedures used for the relaxation IAT was identical to the arousal IAT, except the categories that appeared at the top of the screen were "Relaxation" and "Neutral," with words such as peaceful or average appearing in the center of the screen. Internal consistency among the practice and test combination blocks was .69 for the arousal IAT and .64 for the relaxation IAT. 
Explicit alcohol expectancies. Arousing and sedating alcohol expectancies were assessed using explicit versions of the IATs, consistent with previous work in this area (Thush et al., 2008). Specifically, positive/arousing items were derived from the arousal IAT and positive/sedating expectancy items were derived from the relaxation IAT (Appendix D4). Sample items include "Alcohol makes me feel energetic" and "Alcohol helps me feel relaxed." Response options range from $0=$ "strongly disagree" to 4 "strongly agree." Coefficients alpha were .87 and .82 for the arousal and relaxation expectancy scales, respectively.

\section{Executive Functions Measures}

Inhibition. Response inhibition was assessed using computerized version of the reliable and well-validated Stroop Color and Word Test (Stroop, 1935; Golden, 1978). The Stroop test measures the ability to inhibit an automatic response, making it an appropriate test of prepotent response inhibition for the current study. In the practice block, participants were presented with symbols (e.g., "\%\%\%\%", "\&\&\&\&", “== = =", and "\#\#\#\#”) over 48 trials. The symbols appeared in different colors (e.g., blue, green, yellow, red), and participants were asked to indicate the color of the symbols by selecting appropriate response keys (e.g, "E" for blue, "F" for green, "J" for yellow, and "i" for red). In the test block, the words "red," "green," "blue," and "yellow" appeared on the screen. This block included 24 congruent trials (e.g., "red" is printed in the color red) and 24 incongruent trials (e.g., "blue" is printed in the color yellow) presented in random order. Participants were asked to indicate the color the words appeared in, requiring them to inhibit the automatic tendency of reading the printed word during incongruent trials. In previous work, test-retest reliabilities 
ranged from .73 to .86 for the various portions of the test administered in the original format with time intervals ranging from 1 minute to up to 10 days. A single score was calculated to measure inhibition abilities by subtracting the number of errors on incompatible trials from the number of errors on compatible trials. Thus, higher levels on this measure indicate greater inhibition ability.

Working memory. Working memory abilities were assessed using the LetterNumber (L-N) Sequencing subtest of the Wechsler Adult Intelligence Scale - Fourth Edition (WAIS-IV; Wechsler, 2008) and the Subject-Ordered Pointing Task (SOPT; Petrides \& Milner, 1982). The L-N subtest has been shown to be correlated with most of the indices drawn from the SOPT, the measure of working memory ability previously used in this area (e.g., Grenard et al., 2008; Thush et al., 2008) and the tasks were found to measure the same component of working memory, namely, the ability to temporarily store, monitor, and retrieve information (Pukrop et al., 2003). In the L-N Task, participants were read a string of numbers and letters and were asked to repeat the numbers first, in ascending order, followed by the letters, in alphabetical order (Appendix D5). In previous work, the internal consistency values for L-N Sequencing subtest were alpha $=.90$ for individuals aged $18-19$ and alpha $=.85$ for individuals aged 20-24 (Wechsler, 2008). The test-retest reliability coefficient for the test was $r=.83$ for individuals aged 16-29 (average test-retest time interval was 22 days).

In the computerized SOPT, participants were asked to select one of multiple images that appear on the screen. The placement of the images then changed and the participants were asked to select another image not previously selected. An error 
occurred when a participant selected the same image more than once within a trial. In previous work, the SOPT has demonstrated strong internal reliability when overall error scores are tabulated across trials, with test-retest reliability of $r=.82$ over a mean of 42.7 days (Ross, Hanouskova, Giarla, Calhoun, \& Tucker, 2007). In the current study, a score was calculated for this measure by summing the number of correct responses across the three trials, thus higher scores reflect greater working memory ability. Coefficient alpha for our sample on the SOPT was .81. Due to the low correlation of only $r=.13$ between scores on L-N Task and the SOPT, these scores could not be combined to create a single index of working memory ability. The L-N Task was selected as the measure of working memory for the current study because it has demonstrated strong reliability while having a relatively higher ceiling than the SOPT. 


\section{CHAPTER 4}

\section{FINDINGS}

\section{Preliminary Data Analysis}

Univariate statistics. Prior to testing the major hypotheses, preliminary data analysis was conducted to determine whether the assumptions underlying the inferential statistics to be used were met (Harlow, 2005). Univariate analyses were conducted to examine the data for implausible or impossible responses and to determine whether the assumption of normality (e.g., skewness values $<|2.0|$ and kurtosis values $<|4.0|$ ) were met for the distribution of scores of the variables. With the final sample of 205 participants included in the analysis, none of the measured variables displayed problems with normality.

Bivariate correlations. Bivariate correlations were examined to detect the presence of collinearity among independent variables $(r>.85-90)$ so, if present, the issue could be resolved by either removing one of the collinear variables or combining them (Harlow, 2005; Hatcher, 1994; Tabachnick \& Fidell, 2001). Examination of bivariate correlations among exogenous variables did not indicate collinearity with values ranging from .00 to .58 (Table 1).

Missing data. As previously noted, one participant did not provide her age and was excluded from the final sample. Based on an administrative error, L-N Sequencing was missing for one individual. There was one individual missing a value on the Stroop Interference Test. Individuals with missing values on any of the variables being analyzed were omitted from that analysis which resulted in between 45 participants being excluded from any major analysis. With 205 participants, this 
means between $2.0 \%$ and $2.4 \%$ of participants were dropped from various analyses due to missing data. There were 11 participants who were missing 1-2 of the 30 values on the timeline follow-back questionnaire. Because this measure was needed to construct three of the four indicators for our latent dependent variable, any missing values on this questionnaire would have excluded participants from all analyses. To avoid losing all data from these individuals, these missing drinking days were estimated by averaging how much participants drank on the same day of the week for the rest of the month. For example, for a participant who did not report how much they drank on a particular Saturday but reported drinking 2, 0, 3, and 5 drinks on other Saturdays, a value of 2.5 was assumed for the missing Saturday.

Alcohol use and problems. On average, female participants drank 4.5 standard drinks per week $(S D=5.2)$ while males drank $7.8(S D=7.2)$. The maximum number of drinks on one day in the past 30 days by female participants was $4.8(S D=$ 4.1) and for males it was $8.3(S D=6.1)$. Female participants had on average 2.5 heavy drinking days in the previous 30 days $(S D=3.4)$, defined as having four or more drinks on a single day. For male participants, there was an average of 3.2 heavy drinking days $(S D=3.1)$ in the previous 30 days, defined as having five or more drinks on a single day. In terms of alcohol-related problems, $89 \%$ of female participants reported experiencing at least one problem in the previous 12 months, with the most common problems being "I have had a hangover (headache, sick stomach) the morning after drinking ( $n=114,76 \%)$, "While drinking, I have said or done embarrassing things" ( $n=97,64.7 \%)$, and "I have felt very sick to my stomach or thrown up after drinking" $(n=83,55.3 \%)$. Fully $96 \%$ of male participants reported 
experiencing at least one alcohol-related problem in the previous 12 months. The three most common reported problems for males were the same as those reported by females and included "I have had a hangover (headache, sick stomach) the morning after drinking" ( $n=41,74.6 \%)$, "I have felt very sick to my stomach or thrown up after drinking" ( $n=39,70.9 \%)$, and "While drinking, I have said or done embarrassing things" $(n=36,64.5 \%)$.

\section{Model Specification}

Confirmatory factor analysis. Confirmatory factor analysis (CFA) was conducted for the alcohol involvement latent variable to ensure adequate construct measurement using multiple indices of model fit, including the Non-Normed Fit Index (NNFI), Comparative Fit Index (CFI), and Root Mean Square Error of Approximation (RMSEA; Hatcher, 1994).

Indications that the model is a good fit with the data include minimal values of $>.9$ for NNFI and CFI and <.10 for RMSEA (Hatcher, 1994; Kline, 2005). The latent construct of alcohol involvement was estimated with three indicators of alcohol use (e.g., average weekly number of drinks, frequency of heavy drinking episodes, and peak number of drinks) and one indicator of alcohol-related problems. Initial CFA results for the alcohol involvement factor generally displayed acceptable fit, $\chi^{2}(2, N=$ $205)=14.56, p<.001, \mathrm{CFI}=.98, \mathrm{NNFI}=.94$. RMSEA was above the acceptable limit with a value of .18. However, fitting the model to the data resulted in a negative variance for number of typical drinks per week, an impossible solution known as a "Heywood case" (Kline, 2005, p. 114). This problem was corrected by computing log transformations of the each of the four indicators of alcohol involvement. Results of 
the corrected model displayed improved fit, $\chi^{2}(2, N=205)=7.81, p<.05, \mathrm{CFI}=.99$, NNFI $=.98$. The RMSEA was reduced but remained elevated with a value of .12 . We decided to retain this model given the acceptable levels of fit across most indices.

Structural equation models. In order to test our substantive hypotheses, we estimated four structural equation models using maximum likelihood estimation that incorporated both measured (manifest) and unmeasured (latent) variables. In Model 1, we examined the moderating effects of working memory abilities on arousal associations as predictors of alcohol involvement. Manifest exogenous variables were covaried and included sex as a covariate due to anticipated sex differences on alcohol outcomes, working memory, arousal implicit associations, and arousal expectancies. In order to test for the hypothesized moderating effect of working memory abilities on implicit associations and expectancies, two additional manifest variables were included in the model: one reflecting the interaction between working memory and arousal implicit associations (Hypothesis 1A), and the other reflecting the interaction between working memory and arousal expectancies (Hypothesis 1B). As recommended (Aiken \& West, 1991), prior to multiplicatively creating interaction terms, the variables comprising the interaction term were centered $($ Mean $=0)$ to reduce multi-collinearity. Model 2 was constructed to be almost identical to Model 1 with inhibition taking the place of working memory. Thus, the interaction terms represented the interactions between inhibition and arousal implicit associations (Hypothesis 2A), as well as the interaction between inhibition and arousal expectancies (Hypothesis 2B). In Model 3, we modified Model 1 to examine relaxation associations in place of arousal associations. Interaction terms were created 
to detect interactions between working memory and relaxation implicit associations (Hypothesis 3A), as well as interactions between working memory and relaxation expectancies (Hypothesis 3B). Model 4 was nearly identical to Model 3, except working memory was replaced with inhibition to detect interactions between inhibition and relaxation implicit associations (Hypothesis 4A) and between inhibition and relaxation expectancies (Hypothesis 4B).

The major study-related analyses involved tests of interactions between cognitive and neuropsychological variables. Specifically, working memory abilities were expected to interact with arousal implicit associations to predict current alcohol involvement (Hypothesis 1A). Initial support for this hypothesis would be indicated by a significant path between the interaction term of working memory and implicit associations and alcohol involvement. If the interaction path was significant, the presence of moderation of working memory ability was explored using simple slope analysis (Aiken \& West, 1991). For example, one set of simple slope analyses would probe our hypothesized significant interaction between working memory abilities and implicit associations to predict our dependent variable (alcohol involvement). In order to accomplish this, we chose three levels of working memory abilities for comparison, including its mean, one standard deviation below its mean, and one standard deviation above its mean. The three resulting simple regression equations would reflect the regression of alcohol involvement onto implicit associations at varying levels of working memory. These simple regression equations would be plotted to illustrate whether the regression of alcohol involvement on implicit associations differs as a function of working memory levels, which would support our hypothesis of the 
moderation of working memory abilities. Each of the remaining hypotheses was tested in the same manner.

\section{Tests of Study Hypotheses}

Hypotheses 1A and 1B: Arousal associations and working memory. In

Model 1 (see Figure 1), we examined relations between working memory abilities, arousal implicit alcohol associations, arousal expectancies and alcohol involvement. Results indicated good fit, $\chi^{2}(20, N=205)=37.60, p<.01, \mathrm{CFI}=.98, \mathrm{NNFI}=.95$, and RMSEA = .07. After controlling for correlations among exogenous variables (see Table 1$)$, main effects of sex $(\beta=.22, p<.01)$ and arousal expectancies $(\beta=.34, p<$ .001) on alcohol involvement were observed, such that males and individuals reporting stronger arousal expectancies reported significantly higher levels of alcohol involvement. In contrast to expectations, a main effect of arousal implicit associations on alcohol involvement was not observed. Significant interactions were not observed between working memory and arousal implicit associations, or between working memory and arousal expectancies. Thus, support for Hypotheses 1A and 1B was not obtained. Examination of $R^{2}$ indicated that $16 \%$ of the variance in alcohol involvement was explained in this model.

Hypotheses 2A and 2B: Arousal associations and inhibition. In the second model, we examined relations among inhibition abilities, arousal implicit associations, and arousal expectancies (Figure 2). Results indicated good model fit, $\chi^{2}(20, N=205)$ $=52.26, p<.001, \mathrm{CFI}=.96, \mathrm{NNFI}=.91$, and $\mathrm{RMSEA}=.09$. After controlling for correlations among exogenous variables (see Table 1), main effects of sex $(\beta=.21, p$ $<.01)$ and arousal expectancies $(\beta=.33, p<.001)$ on alcohol involvement were again 
observed, such that males reported significantly higher levels of alcohol involvement than females. In contrast to expectations, main effects of inhibition, arousal implicit associations, and arousal expectancies on alcohol involvement were not observed. Significant interactions were not observed between inhibition and arousal implicit associations, or between inhibition and arousal expectancies. Thus, support for hypotheses $2 \mathrm{~A}$ and 2B was not obtained. Results of $R^{2}$ indicate that $16 \%$ of the variance in alcohol involvement was explained by the model.

Hypotheses 3A and 3B: Relaxation associations and working memory. In the third model, we examined relations among working memory abilities, relaxation implicit associations, and relaxation expectancies (Model 3). Results indicated good model fit, $\chi^{2}(20, N=205)=30.53, p>.05, \mathrm{CFI}=.99, \mathrm{NNFI}=.97$, and RMSEA $=.05$. After controlling for covariances among exogenous variables (see Table 1), main effects for $\operatorname{sex}(\beta=.21, p<.01)$ and relaxation expectancies $(\beta=.24, p<.01)$ were observed, such that male participants and those indicating stronger relaxation expectancies reported greater levels of alcohol involvement. In contrast to expectations, a main effect of relaxation implicit associations on alcohol involvement was not observed. Significant interactions were not observed between working memory and relaxation implicit associations, or between working memory and relaxation expectancies. Thus, support for hypotheses 3A and 3B was not obtained.

Results of $R^{2}$ indicate that $13 \%$ of the variance in alcohol involvement was explained by the model.

Hypotheses 4A and 4B: Relaxation associations and inhibition. In the fourth model, we examined relations among inhibition abilities, relaxation implicit 
association, and relaxation expectancies (Figure 4). Results indicated good model fit, $\chi^{2}(20, N=205)=36.60, p<.05, \mathrm{CFI}=.98, \mathrm{NNFI}=.95$, and RMSEA $=.06$. Results of $R^{2}$ indicate that $14 \%$ of the variance in alcohol involvement was explained by the model. After controlling for correlations among exogenous variables (see Table 1), main effects were observed for $\operatorname{sex}(\beta=.21, p<.01)$, relaxation implicit associations $(\beta=.14, p<.05$, one-tailed $)$, and relaxation expectancies $(\beta=.28, p<.001)$. Male participants reported greater levels of alcohol involvement. Additionally, as anticipated, stronger relaxation implicit associations and stronger relaxation expectancies were associated with greater levels of alcohol involvement. A significant interaction effect between inhibition and relaxation implicit associations was observed $(\beta=-.15, p<.05)$. This interaction effect was probed using simple slope analysis as detailed previously (see Figure 5). At one standard deviation below the mean of inhibition, the main effect of implicit relaxation associations on alcohol involvement was significant $(\beta=.34, p<.05)$. At one standard deviation above the mean of inhibition, the main effect of implicit relaxation associations on alcohol involvement was not significant $(\beta=-.05, p>.05)$. Thus, results of simple slope probing supported the hypothesis that relations between implicit relaxation associations and alcohol involvement would be moderated by inhibition abilities (Hypothesis 4A). Specifically, individuals with weaker inhibition abilities demonstrated stronger relations between implicit associations and alcohol involvement, while individuals with stronger inhibition abilities demonstrated weaker relations between implicit associations and alcohol involvement. In contrast to expectations, a main effect of 
inhibition on alcohol involvement was not observed. Also in contrast to expectations, an interaction effect between inhibition and relaxation expectancies was not observed.

\section{Ancillary Analyses}

\section{Arousal and relaxation associations in heavy drinkers}

Given the stronger alcohol associations held by heavy drinkers as summarized previously, we examined implicit arousal and relaxation associations and expectancies with the top third heaviest drinking participants and the moderation of neuropsychological abilities in this group. Of the overall sample of 205 participants, approximately one-third reported no heavy drinking episodes in the previous 30 days $(n=72,35.1 \%)$ while $28.8 \%$ of participants reported $1-2$ heavy drinking episodes in the previous 30 days $(n=59)$. For the current analyses, participants who reported 3 or more gender-specific heavy drinking episodes in the previous thirty days were included $(n=74,36.1 \%)$. We were not able to use structural equation modeling given the smaller size of this sample, and so we analyzed these data using multiple regression analyses designed to parallel the analyses used with the full sample. We conducted four hierarchical multiple regression analyses. In each of the regression analyses, the dependent variable was an index of alcohol involvement created by summing the standardized values on average weekly number of drinks, maximum number of drinks in the previous 30 days, number of heavy drinking episodes in the previous 30 days, and alcohol-related problems. In the first step of each regression, sex and either arousal or relaxation associations were entered. In the second step, interaction terms between associations and either working memory or inhibition were entered. As anticipated, results from the final regression models indicated significant 
main effects for sex, arousal implicit associations, and arousal expectancies among the heaviest drinkers (all $p$ ’ $<.05)$. The main effect for relaxation expectancies approached significance $(p=.053)$ while relaxation implicit associations did not show a significant main effect $(p>.05)$. There were no significant interaction effects observed with this group of participants. 


\section{CHAPTER 5}

\section{CONCLUSION}

In the present research, we studied relations among alcohol associations, neuropsychological functioning, and alcohol involvement. We sought to extend prior research to examine a broad range of implicit and explicit cognitions, as well as a number of validated measures of neuropsychological functioning. Consistent with dual process models of alcohol involvement, our overarching hypothesis was that associations between implicit and explicit cognitions and alcohol involvement would vary according to neuropsychological functioning. Specifically, we hypothesized that individuals with stronger inhibition and working memory abilities would show weaker relations between arousal and relaxation implicit associations and alcohol involvement, while showing stronger relations between arousal and relaxation expectancies and alcohol involvement. On balance, support for this hypothesis was modest and limited to one of the four domains we examined. Nonetheless, the present research extends current knowledge by incorporating multiple types of associations and neuropsychological domains within a single study while focusing on a population of American college students. We consider our findings in the context of the larger literature next.

Our finding that male participants reported higher levels of alcohol use and problems than female participants was expected given well-established relations between gender and alcohol-involvement (Wechsler, Lee, Kuo, \& Lee, 2000). Relaxation cognitions, both implicit and explicit, were also related to greater levels of alcohol involvement. Additionally, arousal expectancies were related to increased 
alcohol involvement. That various types of alcohol associations were directly related to alcohol involvement, including relaxation implicit associations, relaxation expectancies, and arousal expectancies, is consistent with findings from previous research (Grenard et al., 2008; Houben \& Wiers, 2009; Jajodia \& Earleywine, 2003; Palfai \& Wood, 2001; Thush et al., 2008; Wiers et al., 2002).

In contrast, arousal implicit associations were not directly associated with alcohol involvement in the current sample. This lack of direct association was also found in a related study on positive/arousal associations (Thush et al., 2008), whereas other studies have found arousal implicit associations predict concurrent (Houben \& Wiers, 2006; Houben \& Wiers, 2009) and prospective (Thush et al., 2008; Wiers et al., 2002) alcohol involvement. Consistent with related research, neither of the neuropsychological functions we measured, including inhibition and working memory, was associated with alcohol involvement directly (Houben \& Wiers, 2009; Thush et al., 2008).

As detailed previously, interaction effects between the executive functions and alcohol associations constituted the major hypotheses of the present study. Support for the hypothesis that inhibition would exhibit a moderating effect on relaxation implicit associations involving alcohol was observed. We found relaxation implicit associations and expectancies independently related to alcohol involvement, with a significant interaction occurring between inhibition abilities and relaxation implicit associations. Further analysis of this interaction revealed that individuals with stronger inhibition abilities showed weaker relations between relaxation implicit associations and alcohol involvement. This finding suggests that individuals with 
stronger inhibition abilities are able to inhibit automatic alcohol-related associations that are triggered in the environment which could otherwise serve to increase alcohol involvement. Individuals with lower inhibition abilities would not be as wellequipped to inhibit these associations once they are activated, and thus would show stronger relations between relaxation implicit associations and involvement. This is the pattern that was observed and it is consistent with our hypothesis as well as findings from a related study (Houben \& Wiers, 2009). These findings suggest that certain neuropsychological abilities may moderate relations between alcohol associations and alcohol involvement.

Although inhibition abilities were shown to moderate relations between relaxation implicit associations and alcohol involvement, this pattern did not extend to arousal implicit associations. Support for our hypotheses of a moderating effect of working memory ability on either implicit associations or expectancies was also not observed. These findings are in contrast to some previous research revealing a moderating effect of working memory abilities on implicit alcohol associations (Grenard et al., 2008; Thush et al., 2008). Thus, these findings do not support the view that individuals with stronger working memory abilities are better able to avoid the influence of automatic alcohol associations, nor does it support the notion that alcohol expectancies are more predictive of drinking behavior in people with better working memory abilities.

Comparisons among findings from the current study and the studies we sought to replicate and extend are limited by several factors. Only one of the related previous studies included both implicit associations and expectancies, as we did here (Thush et 
al., 2008). It is notable that the researchers in this study also observed variable support for hypothesized interaction effects. Specifically, none of their three regression models reached significance, while three of our four models did not. By controlling for relations with expectancies, we conducted a more conservative test of relations between implicit associations and alcohol involvement. This is in contrast to the other studies replicated here (Grenard et al., 2008; Houben \& Wiers, 2009). There are also numerous differences in the measurement approach used across studies which limits comparison of findings. For example, Grenard and others (2008) created a word association task to measure implicit associations that simply tallied whether participants provided words related to alcohol when cued with ambiguous word choices. There was no measure of the valence of the associations (e.g., positive or negative), or of the type of association (e.g., arousing or sedating), as well as no measure of alcohol expectancies. The sample for this study also differed in that it only included students from an alternative high school. Finally, the researchers used the Subject-Ordered Pointing Task (SOPT) to measure working memory, whereas we used the Letter-Number Sequencing test. As noted previously, we chose this task given the relatively higher ceiling due to the presumably higher cognitive abilities in the current sample. Thus, although these researchers also examined the moderating role of working memory on alcohol-related associations, their measurement approach and sample differed from ours.

The methodology employed by Thush and others (2008) with a small sample of Dutch vocational students more closely resembled that of the present study, particularly in regards to their measurement of implicit associations. These 
researchers administered three unipolar IATs to estimate arousal, relaxation, and negative associations. Also consistent with the present study, they assessed expectancies by creating explicit versions of their IATs. However, these researchers also measured working memory with the SOPT. Moreover, the support these researchers observed for a moderating effect of working memory on arousal implicit associations and use was observed with follow-up analyses on a non-significant multiple regression analysis.

The third and final study we sought to replicate and extend is the only study to our knowledge to examine the moderating role of inhibition on implicit alcohol associations. Houben and Wiers (2009) administered two IATs to a Dutch college student sample, with one (bipolar) IAT assessing positive vs. negative associations and the other (unipolar) IAT assessing arousal vs. neutral associations. While this study is similar to the current study in several ways, including their use of the Stroop as a measure of inhibition and their inclusion of college students, several differences between our approach and their approach exist. For example, these researchers did not assess expectancies or any other neuropsychological domain, the study took place outside of the United States, and participation was done exclusively online.

\section{Dual Process Model}

The current study does not constitute a comprehensive test of the dual process model as applied to alcohol involvement. However, our inclusion of both implicit associations and expectancies is consistent with the central tenet of this approach, which has been used to study a variety of health behaviors (Hofmann et al., 2009). Our finding that expectancies were related to alcohol involvement when the effects of 
implicit associations were controlled is consistent with the model's conceptualization of explicit cognitions as well as prior related research (Jajodia \& Earleywine, 2003; Palfai \& Wood, 2001; Wiers et al., 2002). Neuropsychological abilities, namely, working memory and inhibition, are an integral part of a comprehensive dual process model, with emerging evidence implicating these abilities as moderators of relations between alcohol associations and alcohol involvement (Grenard et al., 2008; Houben \& Wiers, 2009; Thush et al., 2008). In a replication of Houben and Wiers (2009), our results support the important role of inhibition abilities as a moderator of relations between implicit associations and alcohol involvement.

\section{Detecting Interaction Effects}

In addition to the methodological differences between our study and the studies previously described, there are other, more general, methodological explanations for some of our non-significant interaction effects. According to McClelland and Judd (1993), detecting interaction and moderator effects can be a significant challenge, even when there is strong theoretical reason to suspect the presence of these effects. One source of this difficulty concerns the variances of the variables used to create the interaction term. McClelland and Judd explain that range restriction in the variance of variables are exacerbated when they are multiplicatively combined, as done in the present study, resulting in a clustering of observations in the center of a range as opposed to values at more extreme ends of the distribution. One potential solution is oversampling for extreme observations. Given that we did not oversample for participants who would perform at either extreme of our independent variables, (e.g., individuals with very high or low executive functions, or heavy drinkers who would 
have stronger alcohol associations), our design may have limited our ability to detect some of our hypothesized interaction effects.

\section{Sample Differences Across Studies}

Potential sample differences across studies that may have affected our results include different levels of alcohol consumption, differences in neuropsychological functioning, exclusion of individuals with ADHD or history of loss of consciousness, and differences in age (see Table 2). Each of these possibilities is discussed in turn. For example, although American college students frequently engage in heavy alcohol use and are at risk for significant alcohol-related problems (Perkins, 2002), this population may differ from truly "high risk" samples in important ways. In addition, it is likely that our sample had at least average cognitive abilities. In previous studies on the moderating effect of cognitive abilities, researchers studied younger students of alternative and vocational students (Grenard et al., 2008; Thush et al., 2008). Our sample performed within the average range in terms of working memory abilities in comparison to the normative sample used in WAIS-IV development (Wechsler, 2008), with an average score of $19.8(S D=2.4)$, compared to a score of 20 constituting the $50^{\text {th }}$ percentile for the normative sample. In terms of inhibition abilities, the one previous study in this area with a college student sample (Houben \& Wiers, 2009) selected hazardous drinkers, a potentially important difference to be discussed next.

Not targeting heavy drinkers in the present research may also account for some of the differences in our findings, as compared to those in which heavy drinkers were targeted (Grenard et al., 2008; Houben \& Wiers, 2009; Thush et al., 2008). The only eligibility requirement in terms of alcohol use in the present study was that individuals 
must have consumed alcohol at least once in their lifetime. Therefore, light drinkers (and even individuals who did not drink at all in the previous 30 days) were included in our final sample. Previous research has shown that alcohol associations vary depending on one's drinking levels, with heavy drinkers showing stronger positive or arousal associations (Houben \& Wiers, 2006; Thush \& Wiers, 2007; Wiers et al., 2002) compared to light drinkers. It is possible that the lack of support for three of our four main hypotheses were due to insufficient heavy drinkers being present in our sample.

To further examine this possibility, we compared the levels of heavy drinking in our sample to U.S. national college student survey data from the College Alcohol Study, which had a very large sample of more than 14,000 college students (CAS; Wechsler et al., 2000). Levels of abstention were quite similar, while past two weeks heavy episodic drinking was higher in our sample (51\%) as compared to the CAS sample (40\%). Nonetheless, it also appears that frequent heavy episodic drinking was substantially lower, reported by $(21.4 \%)$ in our sample, compared to $33.8 \%$ in the CAS. These differences lend some credence to the possibility that the more modest associations between implicit and explicit cognitions and alcohol use previously observed among lighter drinkers may have impacted our ability to detect hypothesized moderation effects. We explored this possibility with ancillary multiple regression analyses with only the top third of the heaviest drinkers in our sample, with no evidence for a differential pattern, but these analyses were substantially limited by sample size $(n=74)$. 
Neuropsychological functioning levels may be another important difference in our sample versus samples in related work. Whereas our sample was on average 19 years old, the samples in related research on the moderating effect of working memory were typically younger; with an average age of about 16 years (Grenard et al., 2008; Thush et al., 2008). This is relevant since executive functions continue to mature into adulthood, and so performance on tests of neuropsychological abilities is lower and more variable at younger ages. Of the three studies we sought to replicate and extend, only one targeted college students, and our finding of a moderating effect of inhibition abilities on implicit associations is consistent with this study (Houben \& Wiers, 2009). Our sample may have also differed from these other samples in terms of psychological functioning. For example, in an explicit attempt to eliminate potential confounding variables, we excluded 36 individuals who had received a formal diagnosis of Attention Deficit Hyperactivity Disorder (ADHD) and 13 individuals who reported a history of head injury that resulted in loss of consciousness for at least 15 minutes. In the related studies, individuals with ADHD or history of head injury were not excluded (Grenard et al., 2008; Houben \& Wiers, 2009; Thush et al., 2008). Methodologically, there may be benefits to including individuals with a diagnosis of ADHD as these individuals would likely perform more poorly on tests of executive functioning (Homack \& Riccio, 2004), which would introduce greater variability on our measures of interest. As noted previously, this may make interaction effects more readily detectable. Individuals with ADHD are also at greater risk for alcohol-related problems and disorders, despite consuming alcohol in quantities comparable to their non-ADHD counterparts (Rooney, Chronis-Tuscano, \& Yoon, 2012; Wilens, 1998). 
This increased risk for problems and the development of alcohol use disorders has been demonstrated in the absence of comorbid conduct disorder. This suggests that neuropsychological functions in ADHD, such as inhibition and working memory, given their impact on self-restraint and weighing multiple courses of action, may be especially important topics in alcohol research (Baker, Prevatt, \& Proctor, 2012; Gropper \& Tannock, 2009; Homack \& Riccio, 2004; Rooney et al., 2012). However, our goal was to test the moderating role of neuropsychological functioning on relations between alcohol associations and involvement without the confounding presence of ADHD or history of head injury. Therefore, it is because of the significant differences in neuropsychological functioning on these domains that we chose to exclude such individuals from our final sample ${ }^{1}$.

\section{Strengths and Limitations to the Present Research}

There are numerous strengths to the present research. Most notable among them is the breadth of our assessment. This study is the first in this area to examine multiple domains of neuropsychological functioning while assessing both implicit and explicit alcohol cognitions within a single study. Stimuli for the expectancy questionnaires and implicit association tasks were selected based on careful review of the literature and pilot testing. The sample for this study was relatively large and the study protocol was delivered with consistent attention to procedural fidelity, careful training, and ongoing supervision of research staff. In addition, in an extension of prior related research, we utilized structural equation modeling which allowed us to examine alcohol outcomes as a latent variable. 
We took numerous steps to minimize threats to internal validity. At the start of each appointment, staff highlighted the anonymous nature of all responses to encourage honest responding from the participants. An effort prompt was read to each participant after he or she provided informed consent to encourage effort and vigilance. Procedures were in place such that any participant who did not appear to be putting forth adequate effort would be read an additional second prompt, followed by being asked to leave the study if the problem continued. At no time during data collection did staff feel it was necessary to provide additional effort prompts due to concerns over insufficient effort. Supervision of staff was conducted regularly and included weekly group supervision as well as ongoing, individual supervision, during which we reviewed procedures and any problems with data collection, scoring, or entry. In addition, a written log was kept in which research assistants summarized their work each day and any issues that arose. Staff members were unobtrusively present in the room with participants for the duration of each appointment and were thus available at all times. As previously detailed, we used tests and measures demonstrating adequate reliability in prior research and examined their reliability in our sample. In an effort to avoid problems with missing data, staff examined questionnaires at the end of each session for unintentional missing data and obtained the information from the participant, resulting in minimal missing data. In sum, a concerted effort was made to increase the internal validity of the present research as fully as possible and to ensure that the data collected were meaningful.

However, several limitations to the current study should also be noted. Chief among these are limitations related to both the non-representative and homogeneous 
nature of our sample. Our sample only included college students and was

predominately female, therefore results may not generalize to other populations.

Consistent with our expectations based on the demographic breakdown of our university, our sample was homogenous in terms of race and ethnicity, with most participants being white and non-Hispanic. This demographic composition differs substantially compared to the studies we sought to replicate, which were Dutch (Houben \& Wiers, 2009; Thush et al., 2008) or predominately Latino (Grenard et al., 2008). Results obtained from the current sample may also not generalize to populations that differ in terms of drinking level and neuropsychological functioning.

Additional limitations to our findings result from the correlational, crosssectional design of the study. Although we observed numerous significant relationships, it is not possible based on the design of this study to infer that weakened relations between implicit relaxation associations and alcohol involvement is directly caused by inhibition abilities. Another possible area of concern is that our measure of alcohol use was based entirely on self-report. However, participants were assured of the anonymity of their responses and this method of assessing alcohol use has demonstrated reliability (Sobell et al., 1986).

\section{Conclusion and Future Directions}

Alcohol misuse continues to be a significant problem for many individuals. The major purpose of the present research was to increase our understanding of how cognitive and neuropsychological factors may interact to shape drinking behavior. Although the present study does not constitute a test of the dual process model of addictions, the examination of both implicit and explicit cognitive processes as 
important factors in drinking behavior was informed by the model. Support for unique contributions of implicit and explicit processes has received much empirical support as summarized previously. Additional support has been provided here as expectancies related to alcohol involvement after the variance of implicit associations was accounted for.

Research that considers the moderating role of neuropsychological abilities on alcohol associations and involvement is emerging with increasing sophistication. This relatively small body of literature suggests that examination of neuropsychological function will provide a deeper understanding of alcohol involvement. While the current study provides modest support for a moderating role of neuropsychological functions on alcohol associations and involvement, it remains clear that this avenue of research should continue to receive attention as findings will inform preventive and treatment approaches. Specifically, the utility in altering implicit associations and expectancies, as well as the potentially moderating effect of working memory on arousal associations, and inhibition on arousal and relaxation associations, warrant further exploration.

Researchers have recently begun assessing the utility of altering implicit alcohol associations in an effort to reduce alcohol misuse among non-treatment and treatment seeking individuals. Houben, Havermans, and Wiers (2010) demonstrated that negative implicit alcohol associations could be strengthened using a computerized evaluative conditioning task with a sample of Dutch college students. Participants who were randomly assigned to the training condition viewed alcohol-related stimuli that were repeatedly paired with negative pictures. In comparison to participants in 
the control group, these individuals showed significantly stronger negative implicit associations with alcohol after the training, as well as stronger negative expectancies and, of particular interest, less alcohol use in the following week. These findings did not extend to positive expectancies or generalize to another training condition in which participants viewed pictures of faces exhibiting negative emotions. Despite the short follow-up period, this study provides compelling initial evidence that implicit evaluative associations of alcohol-related stimuli may be altered and should continue to be studied.

In related work with male, heavy drinking college students, Wiers, Rinck, Kordts, Houben and Strack (2010) sought to retrain implicit approach tendencies toward alcohol-related stimuli using an Approach-Avoidance Task (AAT). During this task, participants were randomly assigned to either push or pull a joystick depending on the orientation (e.g., portrait or landscape) of a picture. Participants in the condition in which an alcohol approach tendency was trained had $90 \%$ of their pictures oriented so that they were pulling alcohol pictures toward them. Those who showed changes in their alcohol avoid response times after the training AAT subsequently drank less during a taste test than those trained to pull alcohol toward them. These findings suggest that implicit approach tendencies may be modified using a computerized training task.

Finally, in subsequent research on retraining of implicit alcohol associations, Wiers and others tested the effects of implicit retraining using the AAT in a clinical sample of alcoholics (Wiers, Eberl, Rinck, Becker, \& Lindenmeyer, 2011). In this study, there were two experimental conditions in which automatic alcohol associations 
were retrained either implicitly or explicitly using a joystick. Compared to participants in the control conditions, those in the experimental conditions showed a pre- to post-test change in bias from approaching alcohol to avoiding it. Comparison of control and experimental group members one year after treatment termination showed a significant trend toward individuals in the experimental group experiencing less relapse. Thus, these findings again show that cognitive retraining for automatic alcohol associations is possible and may enhance treatment efficacy when added to treatment as usual in clinical populations. Although these studies measured implicit alcohol associations with the AAT rather than the IAT, there is initial evidence that neuropsychological ability may also moderate relations between alcohol approach associations and alcohol involvement. For example, in their study of young at-risk Dutch adolescents (mean age $=13.6$ ), researchers assessed the moderating role of inhibition abilities on automatic alcohol approach associations (Peeters et al., 2012). Scores on the AAT reflected faster reaction times when participants were trained to pull alcohol-related stimuli toward them, compared to pushing them away. Similar to the current study, these researchers found stronger relations between automatic alcohol approach associations and alcohol involvement for individuals with weaker inhibition abilities as measured by the Stroop task.

While research on retraining implicit alcohol associations is emerging, the efficacy of changing alcohol expectancies has received a good deal of research attention. Expectancy challenges, for example, are a type of study in which some participants are given alcohol and others are not (Wood, Capone, Laforge, Erickson, \& Brand, 2007). Participants are not informed of who received a drink containing 
alcohol, and after a group interaction, they are asked to infer who consumed alcohol based on their observations. These individuals are then informed of the impact of expectations on the actual effects of alcohol, with the expectation that changing beliefs about alcohol will effect change in drinking levels. In 2011, Labbe and Maisto conducted a review of 11 alcohol expectancy challenge studies with samples of college students. Findings across the studies suggested that gender-specific expectancy challenges (e.g., groups of either male or female participants) produce the strongest reduction in drinking levels (2011). However, the study with the longest follow-up period showed this effect was no longer present after six months (Wood et al., 2007). Therefore, while directly changing expectancies may be thought of as a more customary or feasible intervention, there is insufficient evidence to warrant the use of this approach in isolation. Research addressing the multiple processes involved in alcohol use, such as the study described here, may inform treatment approaches that also target moderators, such as neuropsychological abilities.

For example, in addition to retraining implicit associations and expectancies, training programs may be used to alter working memory ability in significant and lasting ways. In a longitudinal randomized trial, Brehmer, Westerberg, and Backman (2012) compared the performance of adults who completed an intensive five-week computerized working memory training program (e.g., "CogMed") with controls. Findings revealed significant improvements on related working memory tasks for individuals in the treatment group, with younger adults showing the greatest benefit. Importantly, these results were found with a variety of measures, including those assessing additional skills such as sustained attention, and these improvements 
remained after three-months. According to a review by Klingberg (2010), several related studies produced similar findings such that working memory training in one domain led to improved performance on novel working memory tasks which persisted over time. Taken together, these findings indicate that working memory abilities may indeed be modified with targeted training. Future research examining whether this type of training alters the influence of implicit alcohol associations on alcohol involvement could lead to important advancements in this area of study.

As with working memory ability, research has been conducted on the training of inhibition ability, with some studies focused specifically on alcohol use. In a study of 52 heavy drinking college students in the Netherlands, Houben, Nederkoorn, Wiers, and Jansen (2011) randomly assigned participants to complete a go/no-go task that paired alcohol stimuli with either a go response or a non-response. Alcohol consumption was measured in the laboratory immediately after the training exercise as well as during the following week. The participants who completed the alcohol/no-go (inhibit) condition drank less immediately following the training and showed stronger negative implicit associations to alcohol. In addition, those participants completing the alcohol/go condition drank more immediately following the training program, although they did not show changes in their automatic alcohol associations. Importantly, these effects translated to real-world changes in drinking behavior in the week following the experiment, as participants in the alcohol/no-go (inhibit) condition drank significantly less than they did before the experiment, while those in the alcohol/go condition drank significantly more. Similarly, Jones and Field (2012) sought to retrain inhibition abilities in a sample of heavy drinkers. These researchers 
retrained motor inhibition abilities in the presence of alcohol-related pictures using a modified stop-signal task and found this intervention resulted in less alcohol consumption immediately after in the laboratory. While these finding suggest that inhibition abilities may be altered to effect changes in drinking behavior, subsequent research has suggested that these reductions in drinking resulted from changes in negative implicit associations with alcohol, rather than from improved inhibition skills per se (Houben, Havermans, Nederkoorn, \& Jansen, 2012). Future research should continue to disentangle the components of inhibition training that can result in meaningful changes in drinking behavior.

Taken together with the current findings, the malleability of implicit associations, expectancies, working memory, and inhibition abilities offers promise for more tailored interventions for alcohol misuse. Preventive efforts could be enhanced by knowledge of these interactions by providing individuals with low inhibition and working memory abilities with training on improving these skills, in addition to modifying alcohol expectancies and retraining implicit associations. The significance of neuropsychological abilities on alcohol associations has been demonstrated in various studies, with support for a moderating effect of inhibition abilities shown here. Future research employing longitudinal designs will allow for greater understanding of how neuropsychological abilities and cognitive associations predict future drinking. Stronger support for the moderating role of neuropsychological abilities would be provided by experiments and interventions in which these abilities are strengthened through training and subsequent changes in relations between associations and drinking are observed. Future research should also 
be conducted in an effort to replicate these findings with different subsamples of college students, particularly heavy drinking students, students with diverse cognitive abilities, and students with psychopathology affecting neuropsychological functions, to better determine both the parameters of these moderating effects and how broadly these findings generalize. 


\section{Footnotes}

${ }^{1}$ We re-tested the major hypotheses of this study without excluding individuals with ADHD or a history of TBI. We observed similar main effects. However, the interaction effect between relaxation implicit associations and inhibition abilities was no longer present. 
Table 1

Pearson Product Moment Correlations Among Predictor and Outcome Variables

\begin{tabular}{|c|c|c|c|c|c|c|c|c|c|c|c|}
\hline Variable & 1 & 2 & 3 & 4 & 5 & 6 & 7 & 8 & 9 & 10 & 11 \\
\hline $\begin{array}{l}\text { 1. Sex } \\
\text { 2. Working }\end{array}$ & - & & & & & & & & & & \\
\hline Memory & $.24 * * *$ & - & & & & & & & & & \\
\hline $\begin{array}{l}\text { 3. Inhibition } \\
\text { 4. IAT }\end{array}$ & .02 & .10 & - & & & & & & & & \\
\hline $\begin{array}{l}\text { Arousal } \\
5 . \mathrm{IAT}\end{array}$ & .06 & -.03 & -.08 & - & & & & & & & \\
\hline $\begin{array}{l}\text { Relaxation } \\
6 . \text { Arousal }\end{array}$ & .02 & -.05 & -.06 & .03 & - & & & & & & \\
\hline $\begin{array}{l}\text { Expectancies } \\
\text { 7. Relaxation }\end{array}$ & -.06 & .04 & .04 & -.08 & -.02 & - & & & & & \\
\hline $\begin{array}{l}\text { Expectancies } \\
\text { 8. Quantity- }\end{array}$ & -.05 & .00 & .10 & -.04 & -.01 & $.58 * * * *$ & - & & & & \\
\hline $\begin{array}{l}\text { Frequency } \\
\text { 9. Heavy }\end{array}$ & $.24 * * *$ & .09 & .00 & .09 & .11 & $.26 * * *$ & $.21 * *$ & - & & & \\
\hline $\begin{array}{l}\text { Drinking } \\
\text { 10. Max }\end{array}$ & .09 & .08 & .05 & .07 & .08 & $.26 * * *$ & $.20 * *$ & $.90 * * * *$ & - & & \\
\hline $\begin{array}{l}\text { Drinks } \\
\text { 11. Alcohol }\end{array}$ & $.31 * * * *$ & .11 & -.06 & .11 & $.18^{*}$ & $.25 * * *$ & $.21 * *$ & $.80 * * * *$ & $.63 * * * *$ & - & \\
\hline Problems & .10 & $.16^{*}$ & .10 & .07 & -.03 & $.38 * * * *$ & $.28 * * * *$ & $.48 * * * *$ & $.45 * * * *$ & $.45 * * * *$ & - \\
\hline
\end{tabular}

Note: $* p<.05 . * * * p<.001 . * * * * p<.0001$ 
Table 2

Sample Characteristics Across Studies

\begin{tabular}{|c|c|c|c|c|}
\hline $\begin{array}{c}\text { Sample } \\
\text { Characteristic }\end{array}$ & $\begin{array}{c}\text { Grenard et al. } \\
\text { (2008) }\end{array}$ & $\begin{array}{l}\text { Thush et al. } \\
\text { (2008) }\end{array}$ & $\begin{array}{c}\text { Houben \& } \\
\text { Wiers }(2009)\end{array}$ & Present study \\
\hline Sample size & $n=145$ & $n=81$ & $n=71$ & $n=205$ \\
\hline Sex & $66.2 \%$ male & $60.0 \%$ male & $88.7 \%$ female & $73.2 \%$ female \\
\hline Ethnicity & $69.7 \%$ Latino & Dutch & Dutch & $79.8 \%$ white \\
\hline Location & USA & Netherlands & Netherlands & USA \\
\hline Mean age & $16.7(S D=0.7)$ & $16.3(S D=1.3)$ & $20.5(S D=2.0)$ & $19.0(S D=1.1)$ \\
\hline Institution(s) & $\begin{array}{l}4 \text { continuation } \\
\text { high schools }\end{array}$ & $\begin{array}{l}4 \text { low level } \\
\text { vocational } \\
\text { schools }\end{array}$ & University & University \\
\hline $\begin{array}{l}\text { Drinking } \\
\text { characteristics }\end{array}$ & $\begin{array}{l}68.3 \% \text { reported } \\
\text { past month } \\
\text { drinking }\end{array}$ & $\begin{array}{l}77.3 \% \text { reported } \\
\text { heavy drinking } \\
\text { in previous } 2 \\
\text { weeks }\end{array}$ & $\begin{array}{l}8.2 \text { average } \\
\text { drinks per week } \\
(S D=9.8)\end{array}$ & $\begin{array}{l}4.5 \text { average } \\
\text { drinks per week } \\
\text { for females ( } S D \\
=5.2) ; 7.8 \\
\text { average drinks } \\
\text { per week for } \\
\text { males }(S D=7.2)\end{array}$ \\
\hline ADHD status & Not excluded & Not excluded & Not excluded & Excluded \\
\hline
\end{tabular}


Figure 1. Model 1: Arousal Working Memory Structural Equation Model

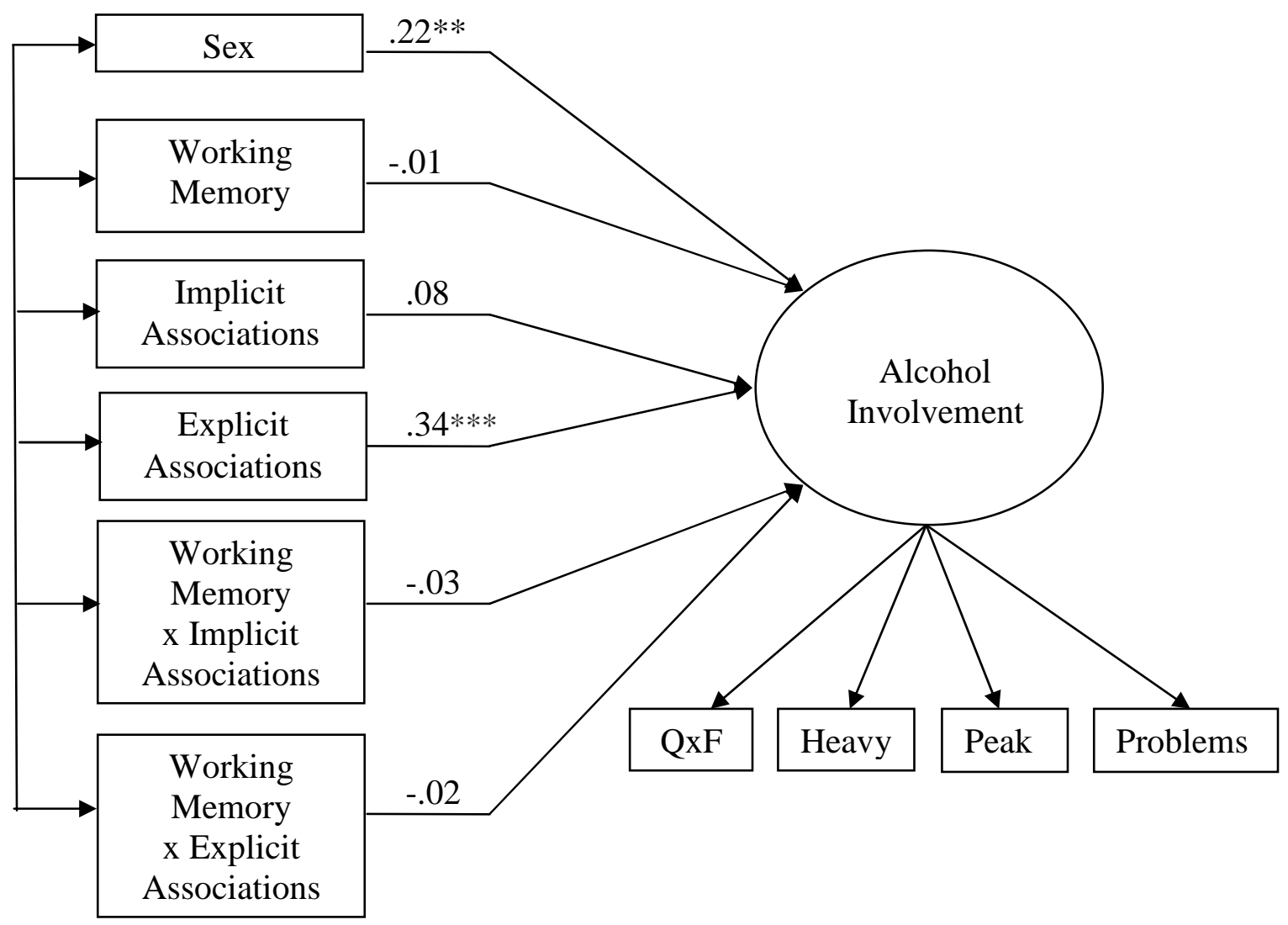


Figure 2. Model 2: Arousal Inhibition Structural Equation Model

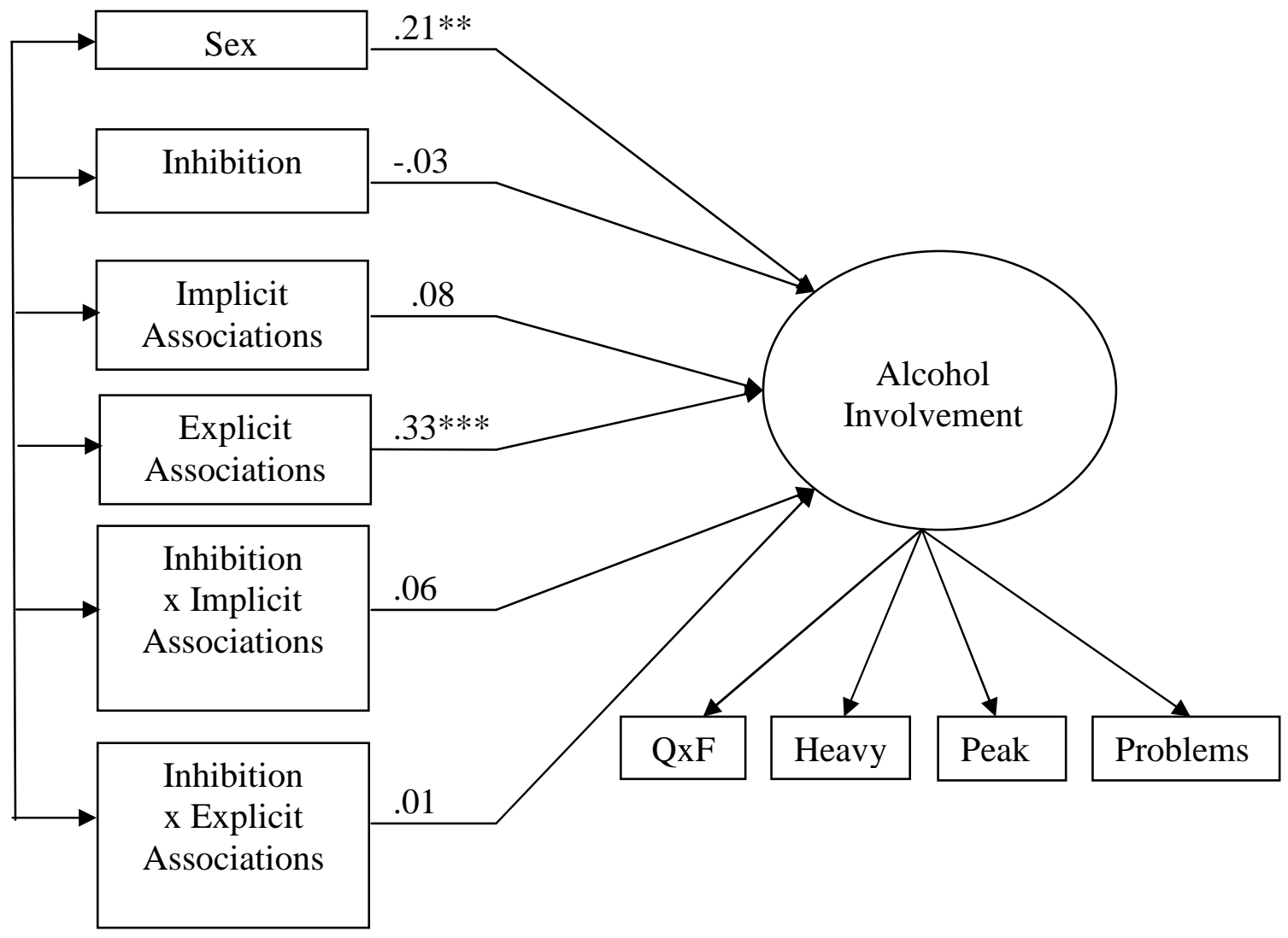


Figure 3. Model 3: Relaxation Working Memory Structural Equation Model

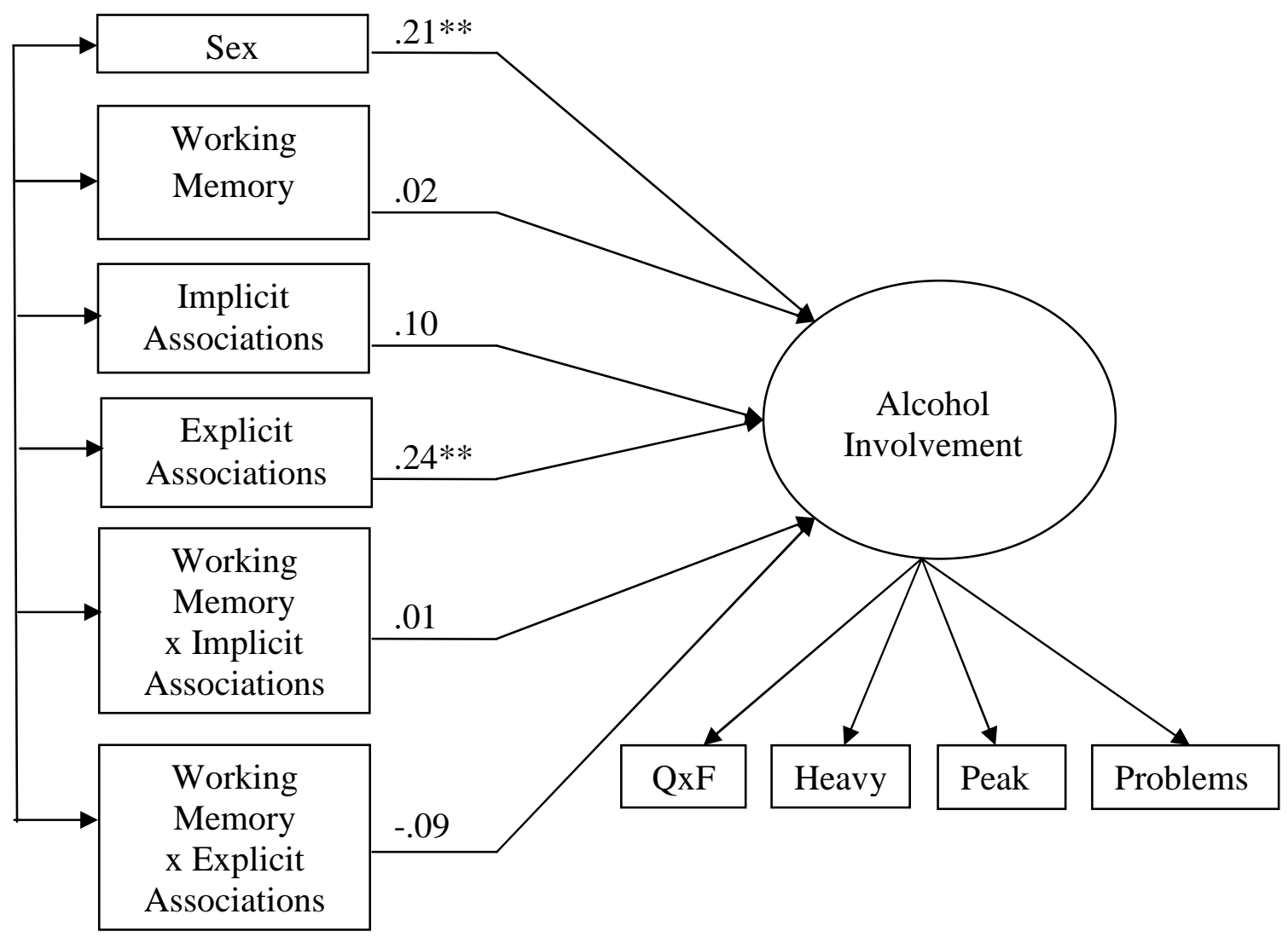


Figure 4. Model 4: Relaxation Inhibition Structural Equation Model

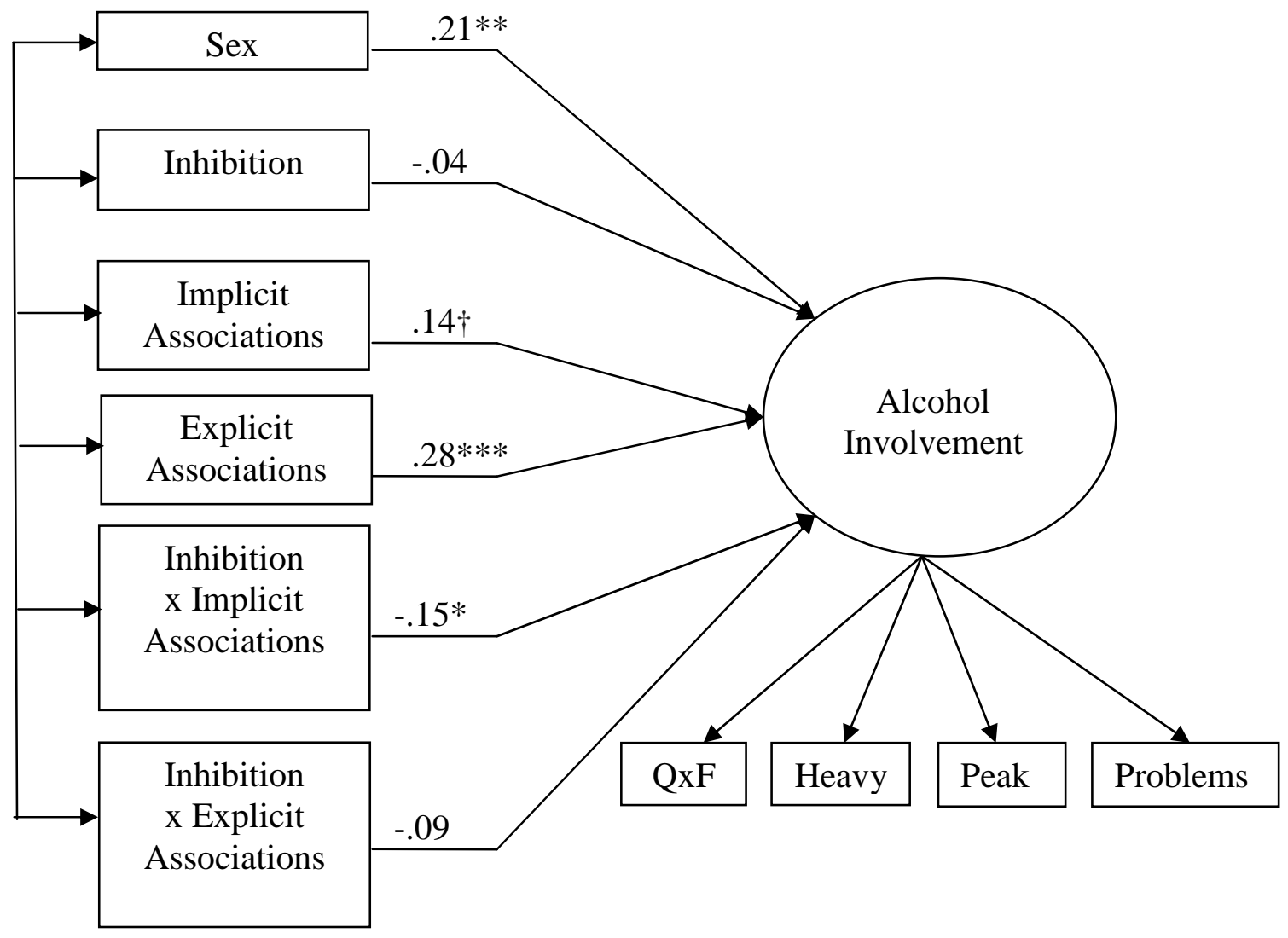


Figure 5. Implicit Relaxation Associations and Inhibition

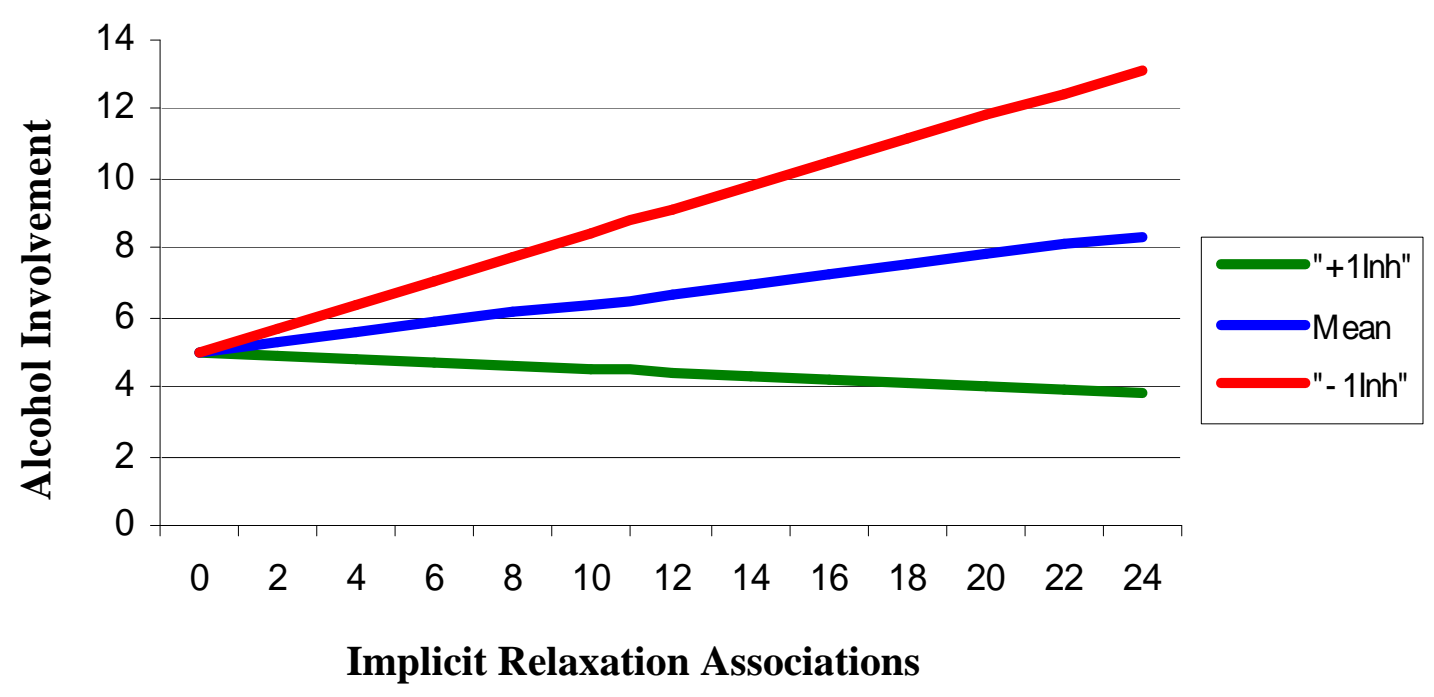




\title{
APPENDIX A
}

\author{
Informed Consent
}

The University of Rhode Island

Department of Psychology

University of Rhode Island

10 Chafee Road

Kingston, RI 02881

Title of Project: College Health Study

\section{CONSENT FORM FOR RESEARCH}

You have been invited to take part in the research study described below. The researcher will explain the study to you in detail. You should feel free to ask any questions you may have. If you have additional questions later, you may contact Professor Mark Wood, Ph.D. at (401) 874-4252. Dr. Wood is the person mainly responsible for this study and will answer any questions you may have. You must be at least 18 years old to participate in this research study.

Description of the project:

This study will examine how alcohol-related thoughts and performance on neuropsychological tests relate to alcohol involvement in college students. The main goal of this study is to better understand how these factors are involved in decisions about alcohol use among college students.

What will be done:

If you decide to take part in this study, you can expect to spend about one hour completing questionnaires and computerized tasks. All assessments and procedures used in this study have been widely used in related research.

Risks or discomfort:

It is not anticipated that you will experience any risks or discomfort by taking part in this study. If at any time you feel uncomfortable by one of the questions, you may choose not to answer it.

Benefits of this study:

Although there will be no direct benefit to you for taking part in this study, you will be helping researchers to understand more about how thoughts and neuropsychological abilities relate to alcohol use in college students. The anonymous information you provide could potentially help others in the future. 


\section{Confidentiality:}

The information you provide in this study is anonymous. Your responses to the assessments used in this study can never be linked to you in any way.

At the end of this consent form, you will be asked to provide your name and signature to indicate that you understand your rights as a research participant and agree to participate. This consent form will be kept separately from the assessments you will complete and there will be no way to ever link the signed consent forms with completed assessments.

As an incentive for participation, you have the option of being entered into a drawing to win one of 100 iTunes gift cards valued at $\$ 10$ each. If you would like to be entered into the drawing, you can put your name and a phone number on a card that will be stored in a separate box. When data collection is complete, one hundred names will be randomly chosen from this box and these individuals will be contacted and instructed on how to retrieve their gift cards. The names provided for this drawing will be kept separate from all study-related responses and there will no way to ever link the names for the drawing with the completed assessments.

The computers used in this study will be used exclusively by study staff and are password protected. All paper-based materials will be stored in locked file cabinets in locked reserved laboratory space. Only key study personnel, including the Principal Investigator, student investigator, and research assistants, will have access to collected data. All of the data collected in this study will remain completely anonymous and will be kept no longer than ten years.

In case there is any injury to the subject:

If this study causes you any injury, you should write or call the Primary Investigator, Professor Mark Wood, Ph.D. at (401) 874-4252. You may also call the office of the Vice President for Research, 70 Lower College Road, University of Rhode Island, Kingston, Rhode Island, at (401) 874-4328.

Decision to quit at any time:

The decision to take part in this study is voluntary and entirely up to you. You do not have to participate. If you decide to participate and then change your mind, you may quit at any time. Whatever you decide will in no way jeopardize your grade or status as a student, and you will still receive PIA! credit and be able to participate in the drawing for an iTunes gift card. If you wish to quit, simply inform Andrea Lavigne, M.A. at (401) 218-2155 or Professor Mark Wood, Ph.D. at (401) 874-4252 of your decision.

Rights and complaints:

If you are not satisfied with the way this study is performed, you may discuss your complaints with Andrea Lavigne, M.A. at (401) 218-2155 or Professor Mark Wood, Ph.D. at (401) 874-4252. You may do so anonymously if you choose. In addition, if you have questions about your rights as a research participant, you may contact: 
Office of the Vice President for Research

70 Lower College Road, Suite 2

University of Rhode Island

Kingston, RI 02881

Telephone: (401) 874-4328

By providing your signature below, you indicate that you have read this consent form. Your questions have been answered. Your signature on this form means that you understand the information and agree to participate in this study.

Signature of Participant

Printed Name

Date

Please sign both copies of the consent form and keep one copy for your records.
Signature of Researcher

Printed Name

Date 


\section{Appendix B}

\section{Effort Prompt Script}

FOR EVERY PARTICIPANT: After signing the consent form and before starting the first task, say:

"Before we get started, I want to mention how important it is that you put in your best effort on all of the tasks you will be doing today. Some of the tasks may be difficult, and some may be easy. It is critical to the study that you try your best on every task. If you feel that you need a break, just let me know and we can take a break in between tasks. Please let me know if you have any questions or don't understand something."

ONLY FOR PARTICIPANTS NOT PAYING ATTENTION: If at any time during the study the participant appears not to be paying attention or putting in good effort (e.g., responding unreasonably quickly, does not appear to be taking something seriously, or appears to be guessing), say:

"As I mentioned earlier, it is extremely important that you try your best on each task. This study has taken a great deal of time and effort to put together, and much more time will be spent analyzing the data we collect. We ask that for the remainder of the time you participate that you commit to putting forth your best effort. Will you do that?"

FINALLY, IF YOU NEED TO END THE SESSION: If after repeated prompting the participant is not attending to the tasks, say:

"It seems as though you aren't able to participate in the study fully right now. We can stop now. If you would like to participate in the drawing for the iTunes gift card, please write your name, phone number, and email address on this note card. Thank you for coming in."

Document issues such as this in the log. 


\section{Appendix C}

\section{Debriefing}

"Thank you very much for participating in this study. Next, I'm going to tell you a bit about why we had you complete these tests and what we hope to learn. Please feel free to interrupt me at any time with questions or comments.

The major goals of this study are to examine how alcohol-related thoughts and performance on tests of executive abilities interact to influence drinking. We had you complete several tests of executive abilities, which refer to higher-order thinking abilities like working memory and inhibition. We are interested in how performance in these areas relate to alcohol-related thoughts and behaviors.

We measured automatic thoughts related to alcohol on the computer when we asked you to categorize words that referred to alcoholic and non-alcoholic drinks, as well as arousal, sedation, relaxation, and neutral words. We also measured your reflective thoughts related to alcohol by having you fill out questionnaires about the effect of alcohol and reasons why you drink.

As we reviewed in the consent form at the start of the study, the information you provided is completely anonymous. The consent form you signed will be kept separately from your responses to all questionnaires and there will be no way to link your responses to your name.

Finally, we ask you to not discuss the details of this study with other individuals in your class who may want to participate so as to not bias their responses. Would you agree to do that?

If you would like to receive PIA! credit, submit your signed consent form to your TA. Additionally, if you would like to enter your name into a drawing to receive one of 100 iTunes gift cards, please write your name and a phone number where you can be reached and place it in the drawing box.

Please take the consent form and this debriefing form with you.

Do you have any questions?

Thank you again!" 


\section{Appendix D1}

\section{Demographics Questionnaire}

1.) How old are you?

2.) What is your sex?

$\square$ Female
$\square$ Male
$\square$ Other

3.) What is your marital status?

$\square$ Never married
$\square$ Married
$\square$ Divorced/separated

4.) You are enrolled at URI:

$\square$ Full-time

5.) You are currently a:

$\square$ Freshman

$\square$ Sophomore

$\square$ Junior

$\square$ Senior

$\square$ Other (please indicate how many semesters you have completed:

6.) You currently reside:

$\square$ On-campus in a dormitory

$\square$ On-campus in a fraternity/sorority

$\square$ Off-campus with parents or legal guardians

$\square$ Off-campus not with parents or legal guardians

$\square$ Other (please indicate:

7.) Are you currently a member of a fraternity or sorority?

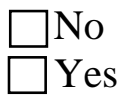

8.) Your current overall GPA is:

$\square<1.00$

$1.00-1.49$

$1.50-1.59$

2.00-2.49

$2.50-2.99$

3.00-3.50

$\square 3.51-4.00$ 
9.) What is your race?

$\square$ American Indian or Alaska Native
$\square$ Asian
$\square$ Black or African American
$\square$ Native Hawaiian or Other Pacific Islander
$\square$ White/Caucasian
$\square$ More than one/Mixed
$\square$ Other (please indicate:

10.) Are you Hispanic or Latino?

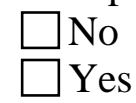

11.) Have you ever been diagnosed with Attention Deficit Disorder (ADD) or Attention Deficit Hyperactivity Disorder (ADHD)?

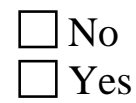

12.) Are you currently taking any medication for psychological or psychiatric problems, including medication for ADD/ADHD?

$\square$ No
$\square$ Yes. If yes, please list the name(s) of the medication(s):

13.) Have you ever experienced a head injury resulting in loss of consciousness lasting 15 minutes or longer?

$\square$ No

14.) Have you ever received treatment for alcohol-related problems?

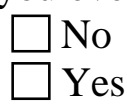

15.) What is the highest level of education achieved by your father?

$\square$ Less than high school/GED

$\square$ High school/GED

Trade school

$\square$ Associate's degree (two-year college degree)

$\square$ Bachelor's degree (four-year college degree)

$\square$ Master's degree

$\square$ Doctorate (M.D., Ph.D., Law degree) 
16.) What is the highest level of education achieved by your mother?

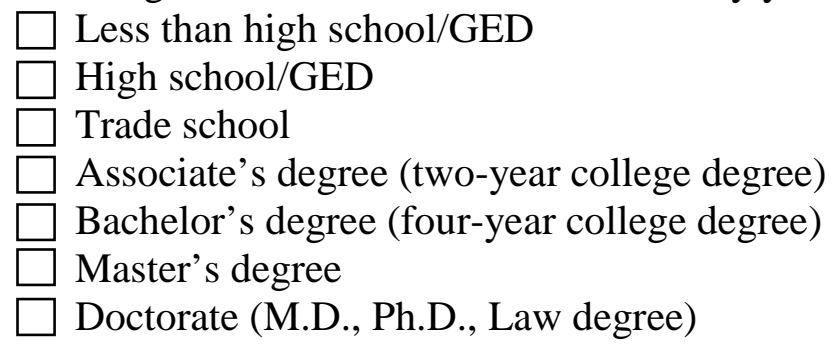

The next set of questions asks about alcohol problems in your family. By "problem drinker" or "alcoholic" we mean a person who has one or more of the following problems related to drinking: physical or emotional problems, problems with a spouse, family, or friends, problems at work, problems with the police (like drunk driving), or a person who seems to spend a lot of time drinking or being hungover.

17.) Do you think your BIOLOGICAL MOTHER is/was a problem drinker or alcoholic?

$\square$ No
$\square$ Yes
$\square$ I do not know my biological mother

18.) Do you think your BIOLOGICAL FATHER is/was a problem drinker or alcoholic?

$\square$ No

$\square$ Yes

I do not know my biological father

19.) Do you think that any of your FULL SIBLINGS is/was a problem drinker or alcoholic?

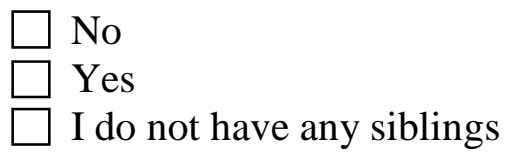

20.) Have any of your OTHER BLOOD RELATIVES (e.g., grandparents, aunts, uncles, cousins) ever been a problem drinker or alcoholic?

$\square$ No
$\square$ Yes
$\square$ Don't know

21.) How many IATs have you previously performed (not including today)?

$\square 0$
$\square 1$
$\square 2$
$\square 3-5$
$\square 6+$




\section{Appendix D2}

\section{Alcohol Use Timeline Follow-back Questionnaire}

Reminders:

- Circle today's date. Count back 30 days by counting back 4 weeks plus 2 additional days.

- Ask about alcohol use for today.

- Fill in days going back as far as they can remember.

- Do not assume what participants mean by "one drink" or "during the week." Ask for specifics.

- Use of personal planners is acceptable.

- Do not enter ranges. Enter exact number.

- Enter the type of drink consumed.

- May use exaggeration to help get exact numbers. For example, if examinee says "a lot" or "a little," it may help to say "does a lot mean 30 beers or 3 beers?"

- Fill in days that have typical patterns, such as 3 drinks every Fridays and no drinks on Tuesdays.

"For this questionnaire, we would like you to recall your drinking for the past 30 days. We would like you to look on this calendar on the last 30 days and let us know how many drinks you had on each day so we can write them in. We want you to be as accurate as possible and we realize it is hard to be $100 \%$ accurate when recalling information. If you can't remember the exact number of drinks you had or the exact day you drank, just give us your best estimate. Here are some standard definitions of what is considered one drink:

$$
\begin{aligned}
& 1 \text { beer }=12 \text { ounces } \\
& 1 \text { glass of wine }=4 \text { ounces } \\
& 1 \text { wine cooler }=12 \text { ounces } \\
& 1 \text { shot }=1 \frac{1 / 4}{4} \text { ounces of liquor } \\
& 1 \text { mixed drink }
\end{aligned}
$$

$40 \mathrm{oz}$. bottle of beer $=3$ drinks

1 six pack of beer $=6$ drinks

1 pitcher of beer $=5$ drinks

1 pint of liquor $=12$ drinks

Before we start, are there any special days, like birthdays or celebrations that we can write on the calendar to help you remember? Standard holidays have been marked."

Do not ask this but if the participant indicates that he or she has not consumed any alcohol in the past 30 days, please choose the appropriate response below.

I have not consumed any alcohol in the past 30 days but I have consumed alcohol in the past.

I have never consumed alcohol. 


\section{Appendix D3}

\section{B-YAACQ}

Please indicate whether you have experienced any of the following in the past year by circling your response.

1. I have taken foolish risks when I have been drinking.

Yes No

2. I have driven a car when I knew I had too much to drink to drive. Yes No

3. When drinking, I have done impulsive things that I regretted later. Yes No

4. I've not been able to remember large stretches of time while drinking heavily.

Yes No

5. I have often found it difficult to limit how much I drink.

Yes No

6. I have felt like I needed a drink after I'd gotten up (that is, before breakfast).

Yes No

7. I have been overweight because of my drinking.

Yes No

8. I have felt very sick to my stomach or thrown up after drinking.

Yes No

9. My drinking has created problems between myself and my boyfriend/girlfriend/spouse/parents, or other relatives.

Yes No

10. I have had less energy or felt tired because of my drinking.

Yes No

11. My physical appearance has been harmed by my drinking.

Yes No

12. My drinking has gotten me into sexual situations I later regretted. Yes No

13. I have become very rude, obnoxious, or insulting after drinking. $\quad$ Yes No 
14. I have passed out from drinking.

Yes No

15. I have spent too much time drinking.

Yes No

16. I have not gone to work or have missed classes at school because of drinking, a hangover, or other illness caused by drinking.

Yes No

17. I have found that I needed larger amounts of alcohol to feel any effect, or that I could no longer get high or drunk on the amount that used to get me high or drunk.

Yes No

18. The quality of my work or school work has suffered because of drinking.

Yes No

19. I often have ended up drinking on nights when I had planned not to drink.

Yes No

20. I have neglected obligations to family, work, or school because of drinking.

Yes No

21. I have had a hangover (headache, sick stomach) the morning after drinking.

Yes No

22. While drinking, I have said or done embarrassing things.

Yes No

23. I have felt badly about myself because of drinking.

Yes No

24. I have woken up in an unexpected place after heavy drinking.

Yes No 


\section{Appendix D4}

\section{Alcohol Expectancies}

The following list describes some effects of alcohol. Because alcohol affects people in different ways, we would like to know which of these effects you experience when you drink alcohol.

Based on your own drinking experience, indicate how much you expect each of these effects when drinking alcohol. If you have never consumed alcohol, indicate how you might expect alcohol to affect you if you had several drinks.

$$
\begin{aligned}
& 0=\text { Strongly disagree } \\
& 1=\text { Disagree } \\
& 2=\text { Neither agree nor disagree } \\
& 3=\text { Agree } \\
& 4=\text { Strongly agree }
\end{aligned}
$$

Strongly

Strongly

Disagree

Agree

1. Alcohol makes me feel sick.

$\begin{array}{lllll}0 & 1 & 2 & 3 & 4\end{array}$

2. Alcohol makes me feel depressed.

$\begin{array}{lllll}0 & 1 & 2 & 3 & 4\end{array}$

3. Alcohol makes me feel tranquil.

$\begin{array}{lllll}0 & 1 & 2 & 3 & 4\end{array}$

4. Alcohol makes me feel down.

$\begin{array}{lllll}0 & 1 & 2 & 3 & 4\end{array}$

5. Alcohol makes me feel talkative.

0

12

6. Alcohol makes me feel calm.

$\begin{array}{lllll}0 & 1 & 2 & 3 & 4\end{array}$

7. Alcohol makes me feel miserable.

$\begin{array}{lllll}0 & 1 & 2 & 3 & 4\end{array}$

8. Alcohol makes me feel happy.

$\begin{array}{lllll}0 & 1 & 2 & 3 & 4\end{array}$

9. Alcohol makes me feel brave.

$\begin{array}{lllll}0 & 1 & 2 & 3 & 4\end{array}$

10. Alcohol makes me feel peaceful.

0

$\begin{array}{llll}1 & 2 & 3 & 4\end{array}$

11. Alcohol makes me feel funny.

$\begin{array}{lllll}0 & 1 & 2 & 3 & 4\end{array}$

12. Alcohol makes me feel relaxed.

$\begin{array}{lllll}0 & 1 & 2 & 3 & 4\end{array}$




\begin{tabular}{llllll}
\hline 13. Alcohol makes me feel comfortable. & 0 & 1 & 2 & 3 & 4 \\
\hline 14. Alcohol makes me feel excited. & 0 & 1 & 2 & 3 & 4 \\
\hline 15. Alcohol makes me feel carefree. & 0 & 1 & 2 & 3 & 4 \\
\hline 16. Alcohol makes me feel withdrawn. & 0 & 1 & 2 & 3 & 4 \\
\hline $\begin{array}{l}\text { 17. Alcohol makes me feel confident. } \\
\text { 18. Alcohol makes me feel sad. }\end{array}$ & 0 & 1 & 2 & 3 & 4 \\
\hline
\end{tabular}




\section{Appendix D5}

\section{Letter-Number Sequencing Task}

Reminders:

- If the examinee begins to respond before you have finished reading the trial, present the remainder of the trial and allow the examinee to respond. Award appropriate credit for the response and say "Remember to wait until I'm finished before you start."

- Do not repeat any trial of an item. If the examinee asks you to repeat a trial, say "I cannot repeat the sequence. Just take your best guess."

- If the examinee provides multiple responses to a trial or self-corrects after his or her initial response, score only the intended response. If it is not clear which one is the intended response, say "You said [insert examinee's response] and you said [insert examinee's response]. Which one did you mean? Score only the intended response.

- Discontinue the task if the participant gets all three trials of the same item incorrect.

- If the participant gets the item correct, circle the correct response.

- For items 3-10, the examinee receives credit if all of the numbers and letters are recalled in the correct sequence, even if the letters are recalled before the numbers. 
"I'm going to say some numbers and letters. After I say them, I want you to say the number first, then say the letter. For example, if I say C-1, you would say 1C. The number goes first, then the letter. Let's practice. A-4."

If the participant is correct, say "That's right" and proceed to trial 1 of item 1.

If the participant is incorrect, say "That's not quite right. I said A-4, so you should say 4-A. The number goes first, then the letter." Proceed to trial 1 of item 1 .

Items $1-2$

*If the examinee does not say the number first, say "Remember to say the number first, then say the letter."

\begin{tabular}{|c|c|c|c|c|}
\hline \multirow{3}{*}{$1 . *$} & & (Correct Responses) & Response Given: & Correct?(Circle) \\
\hline & $2-B$ & $(2-B)$ & & Yes No \\
\hline & D-1 & (1-D) & & Yes No \\
\hline \multirow{4}{*}{ 2.* } & 4-C & $(4-C)$ & & Yes No \\
\hline & E-5 & $(5-E)$ & & Yes No \\
\hline & 3-A & $(3-A)$ & & Yes No \\
\hline & $\mathrm{C}-1$ & $(1-\mathrm{C})$ & & Yes No \\
\hline
\end{tabular}

"Now let's try some with more numbers and letters. I want you to tell me the numbers first, in order, starting with the lowest number. Then tell me the letters in alphabetical order. For example, if I say 2-B-1, then you would say 1-2-B. You say the numbers first, in order, starting with the lowest number. Then say the letters in alphabetical order. Let's practice. D-5-A."

If the participant is correct, say "That's right" and proceed to trial 2.

If the participant is incorrect, say "That's not quite right. I said D-5-A. You should say 5-A-D. You say the numbers first, in order, starting with the lowest number. Then say the letters in alphabetical order." Proceed to trial 2.

Trial 2

"Let's try another one. 2-B-4."

If the participant is correct, say "That's right" and proceed to trial 1 of item 3 .

If the participant is incorrect, say "That's not quite right. I said 2-B-4. You should say 2-4-B. You say the numbers first, in order, starting with the lowest number. Then say the letters in alphabetical order." Proceed to trail 1 of item 3 . 
Items 3-10

'Let's try some more. Remember to say the numbers first, in order, starting with the lowest number. Then say the letters in alphabetical order."

\begin{tabular}{|c|c|c|c|c|}
\hline \multirow{4}{*}{3.} & & (Correct Responses) & Response Given: & Correct? \\
\hline & $5-\mathrm{C}-\mathrm{A}$ & $(5-A-C)$ or $(A-C-5)$ & & Yes No \\
\hline & F-E-1 & $(1-\mathrm{E}-\mathrm{F})$ or $(\mathrm{E}-\mathrm{F}-1)$ & & Yes No \\
\hline & $3-2-A$ & $(2-3-A)$ or $(A-2-3)$ & & Yes No \\
\hline \multirow[t]{3}{*}{4.} & $1-\mathrm{G}-7$ & $(1-7-G)$ or $(G-1-7)$ & & Yes No \\
\hline & H-9-4 & $(4-9-\mathrm{H})$ or $(\mathrm{H}-4-9)$ & & Yes No \\
\hline & 3-Q-7 & $(3-7-Q)$ or $(\mathrm{Q}-3-7)$ & & Yes No \\
\hline \multirow[t]{3}{*}{5.} & $\mathrm{Z}-8-\mathrm{N}$ & $(8-\mathrm{N}-\mathrm{Z})$ or $(\mathrm{N}-\mathrm{Z}-8)$ & & Yes No \\
\hline & M-6-U & (6-M-U) or (M-U-6) & & Yes No \\
\hline & $\mathrm{P}-2-\mathrm{N}$ & $(2-\mathrm{N}-\mathrm{P})$ or $(\mathrm{N}-\mathrm{P}-2)$ & & Yes No \\
\hline \multirow[t]{3}{*}{6.} & V-1-J-5 & $(1-5-J-V)$ or $(J-V-1-5$ & & Yes No \\
\hline & $7-X-4-G$ & $(4-7-G-X)$ or $(G-X-4$ & & Yes No \\
\hline & S-9-T-6 & $(6-9-S-T)$ or $(\mathrm{S}-\mathrm{T}-6-$ & & Yes No \\
\hline
\end{tabular}

7. 8-E-6-F-1 (1-6-8-E-F) or (E-F-1-6-8) —— Yes No

$\mathrm{K}-4-\mathrm{C}-2-\mathrm{S} \quad(2-4-\mathrm{C}-\mathrm{K}-\mathrm{S})$ or $(\mathrm{C}-\mathrm{K}-\mathrm{S}-2-4) \_$Yes No

5-Q-3-H-6 (3-5-6-H-Q) or (H-Q-3-5-6) __ Yes No

8. M-4-P-7-R-2 (2-4-7-M-P-R) or (M-P-R-2-4-7)____ Yes No

$6-\mathrm{N}-9-\mathrm{J}-2-\mathrm{S} \quad(2-6-9-\mathrm{J}-\mathrm{N}-\mathrm{S})$ or $(\mathrm{J}-\mathrm{N}-\mathrm{S}-2-6-9) \_$Yes No

U-6-H-5-F-3 (3-5-6-F-H-U) or (F-H-U-3-5-6) ___ Yes No

9. R-7-V-4-Y-8-F (4-7-8-F-R-V-Y) or (F-R-V-Y-4-7-8)___ Yes No

9-X-2-J-3-N-7 (2-3-7-9-J-N-X) or (J-N-X-2-3-7-9)__ Yes No

M-1-Q-8-R-4-D (1-4-8-D-M-Q-R) or (D-M-Q-R-1-4-8)___ _ Yes No

10. 6-P-7-S-2-N-9-A (2-6-7-9-A-N-P-S) or (A-N-P-S-2-6-7-9)___ Yes No U-1-R-9-X-4-K-3 (1-3-4-9-K-R-U-X) or (K-R-U-X-1-3-4-9) __ Yes No

7-M-2-T-6-F-9-A (2-6-7-9-A-F-M-T) or (A-F-M-T-2-6-7-9) ___ Yes No 


\section{Appendix E}

\section{Word Ratings Form}

Thank you for helping us by completing the enclosed word rating form. Your responses on this form are important to us and will contribute to the design of a research study. We welcome your comments and suggestions. 
Please rate your POSITIVE OR NEGATIVE associations with each of the following words by circling the number that corresponds to your feelings. For example, if I had very positive associations with the word "flower" then I might circle the 9 next to it. If I had very negative associations with the word "insect," I might circle -8. Please read and rate each word carefully but quickly, not spending too much time on any single word. If you are unsure of the meaning of any word, please place a question mark next to the word and move on to the next word. Thank you!

Strongly

Negative

Neutral

1. Talkative

$\begin{array}{lllllllllllllllllllll}-10 & -9 & -8 & -7 & -6 & -5 & -4 & -3 & -2 & -1 & 0 & 1 & 2 & 3 & 4 & 5 & 6 & 7 & 8 & 9 & 10\end{array}$

2. Comfortable

$\begin{array}{lllllllllllllllllllll}-10 & -9 & -8 & -7 & -6 & -5 & -4 & -3 & -2 & -1 & 0 & 1 & 2 & 3 & 4 & 5 & 6 & 7 & 8 & 9 & 10\end{array}$

3. Withdrawn

$\begin{array}{lllllllllllllllllllll}-10 & -9 & -8 & -7 & -6 & -5 & -4 & -3 & -2 & -1 & 0 & 1 & 2 & 3 & 4 & 5 & 6 & 7 & 8 & 9 & 10\end{array}$

4. Average

$\begin{array}{lllllllllllllllllllll}-10 & -9 & -8 & -7 & -6 & -5 & -4 & -3 & -2 & -1 & 0 & 1 & 2 & 3 & 4 & 5 & 6 & 7 & 8 & 9 & 10\end{array}$

\section{Relaxed}

$\begin{array}{lllllllllllllllllllll}-10 & -9 & -8 & -7 & -6 & -5 & -4 & -3 & -2 & -1 & 0 & 1 & 2 & 3 & 4 & 5 & 6 & 7 & 8 & 9 & 10\end{array}$

6. Neutral

$$
\begin{array}{lllllllllllllllllllll}
-10 & -9 & -8 & -7 & -6 & -5 & -4 & -3 & -2 & -1 & 0 & 1 & 2 & 3 & 4 & 5 & 6 & 7 & 8 & 9 & 10
\end{array}
$$

7. Happy

$\begin{array}{lllllllllllllllllllll}-10 & -9 & -8 & -7 & -6 & -5 & -4 & -3 & -2 & -1 & 0 & 1 & 2 & 3 & 4 & 5 & 6 & 7 & 8 & 9 & 10\end{array}$

8. Miserable

$\begin{array}{lllllllllllllllllllll}-10 & -9 & -8 & -7 & -6 & -5 & -4 & -3 & -2 & -1 & 0 & 1 & 2 & 3 & 4 & 5 & 6 & 7 & 8 & 9 & 10\end{array}$

9. Sad

$$
\begin{array}{lllllllllllllllllllll}
-10 & -9 & -8 & -7 & -6 & -5 & -4 & -3 & -2 & -1 & 0 & 1 & 2 & 3 & 4 & 5 & 6 & 7 & 8 & 9 & 10
\end{array}
$$

10. Normal

$$
\begin{array}{lllllllllllllllllllll}
-10 & -9 & -8 & -7 & -6 & -5 & -4 & -3 & -2 & -1 & 0 & 1 & 2 & 3 & 4 & 5 & 6 & 7 & 8 & 9 & 10
\end{array}
$$

11. Calm

$$
\begin{array}{lllllllllllllllllllll}
-10 & -9 & -8 & -7 & -6 & -5 & -4 & -3 & -2 & -1 & 0 & 1 & 2 & 3 & 4 & 5 & 6 & 7 & 8 & 9 & 10
\end{array}
$$


12. General

$\begin{array}{lllllllllllllllllllll}-10 & -9 & -8 & -7 & -6 & -5 & -4 & -3 & -2 & -1 & 0 & 1 & 2 & 3 & 4 & 5 & 6 & 7 & 8 & 9 & 10\end{array}$

13. Excited

$\begin{array}{lllllllllllllllllllll}-10 & -9 & -8 & -7 & -6 & -5 & -4 & -3 & -2 & -1 & 0 & 1 & 2 & 3 & 4 & 5 & 6 & 7 & 8 & 9 & 10\end{array}$

14. Peaceful

$\begin{array}{lllllllllllllllllllll}-10 & -9 & -8 & -7 & -6 & -5 & -4 & -3 & -2 & -1 & 0 & 1 & 2 & 3 & 4 & 5 & 6 & 7 & 8 & 9 & 10\end{array}$

15. Sluggish

$\begin{array}{lllllllllllllllllllll}-10 & -9 & -8 & -7 & -6 & -5 & -4 & -3 & -2 & -1 & 0 & 1 & 2 & 3 & 4 & 5 & 6 & 7 & 8 & 9 & 10\end{array}$

16. Energized

$\begin{array}{lllllllllllllllllllll}-10 & -9 & -8 & -7 & -6 & -5 & -4 & -3 & -2 & -1 & 0 & 1 & 2 & 3 & 4 & 5 & 6 & 7 & 8 & 9 & 10\end{array}$

17. Escape

$\begin{array}{lllllllllllllllllllll}-10 & -9 & -8 & -7 & -6 & -5 & -4 & -3 & -2 & -1 & 0 & 1 & 2 & 3 & 4 & 5 & 6 & 7 & 8 & 9 & 10\end{array}$

18. Regular

$\begin{array}{lllllllllllllllllllll}-10 & -9 & -8 & -7 & -6 & -5 & -4 & -3 & -2 & -1 & 0 & 1 & 2 & 3 & 4 & 5 & 6 & 7 & 8 & 9 & 10\end{array}$

19. Tired

$\begin{array}{lllllllllllllllllllll}-10 & -9 & -8 & -7 & -6 & -5 & -4 & -3 & -2 & -1 & 0 & 1 & 2 & 3 & 4 & 5 & 6 & 7 & 8 & 9 & 10\end{array}$

20. Ordinary

$\begin{array}{lllllllllllllllllllll}-10 & -9 & -8 & -7 & -6 & -5 & -4 & -3 & -2 & -1 & 0 & 1 & 2 & 3 & 4 & 5 & 6 & 7 & 8 & 9 & 10\end{array}$

21. Depressed

$\begin{array}{lllllllllllllllllllll}-10 & -9 & -8 & -7 & -6 & -5 & -4 & -3 & -2 & -1 & 0 & 1 & 2 & 3 & 4 & 5 & 6 & 7 & 8 & 9 & 10\end{array}$

22. Soothed

$\begin{array}{lllllllllllllllllllll}-10 & -9 & -8 & -7 & -6 & -5 & -4 & -3 & -2 & -1 & 0 & 1 & 2 & 3 & 4 & 5 & 6 & 7 & 8 & 9 & 10\end{array}$

23. Cheerful

$\begin{array}{lllllllllllllllllllll}-10 & -9 & -8 & -7 & -6 & -5 & -4 & -3 & -2 & -1 & 0 & 1 & 2 & 3 & 4 & 5 & 6 & 7 & 8 & 9 & 10\end{array}$

24. Typical

$\begin{array}{lllllllllllllllllllll}-10 & -9 & -8 & -7 & -6 & -5 & -4 & -3 & -2 & -1 & 0 & 1 & 2 & 3 & 4 & 5 & 6 & 7 & 8 & 9 & 10\end{array}$

25. Tranquil

$\begin{array}{lllllllllllllllllllll}-10 & -9 & -8 & -7 & -6 & -5 & -4 & -3 & -2 & -1 & 0 & 1 & 2 & 3 & 4 & 5 & 6 & 7 & 8 & 9 & 10\end{array}$

26. Confident

$\begin{array}{lllllllllllllllllllll}-10 & -9 & -8 & -7 & -6 & -5 & -4 & -3 & -2 & -1 & 0 & 1 & 2 & 3 & 4 & 5 & 6 & 7 & 8 & 9 & 10\end{array}$ 
27. Sick

$\begin{array}{lllllllllllllllllllll}-10 & -9 & -8 & -7 & -6 & -5 & -4 & -3 & -2 & -1 & 0 & 1 & 2 & 3 & 4 & 5 & 6 & 7 & 8 & 9 & 10\end{array}$

28. Carefree

$\begin{array}{lllllllllllllllllllll}-10 & -9 & -8 & -7 & -6 & -5 & -4 & -3 & -2 & -1 & 0 & 1 & 2 & 3 & 4 & 5 & 6 & 7 & 8 & 9 & 10\end{array}$

29. Basic

$\begin{array}{lllllllllllllllllllll}-10 & -9 & -8 & -7 & -6 & -5 & -4 & -3 & -2 & -1 & 0 & 1 & 2 & 3 & 4 & 5 & 6 & 7 & 8 & 9 & 10\end{array}$

30. Attractive

$\begin{array}{lllllllllllllllllllll}-10 & -9 & -8 & -7 & -6 & -5 & -4 & -3 & -2 & -1 & 0 & 1 & 2 & 3 & 4 & 5 & 6 & 7 & 8 & 9 & 10\end{array}$

31. Common

$\begin{array}{lllllllllllllllllllll}-10 & -9 & -8 & -7 & -6 & -5 & -4 & -3 & -2 & -1 & 0 & 1 & 2 & 3 & 4 & 5 & 6 & 7 & 8 & 9 & 10\end{array}$

32. Isolated

$\begin{array}{lllllllllllllllllllll}-10 & -9 & -8 & -7 & -6 & -5 & -4 & -3 & -2 & -1 & 0 & 1 & 2 & 3 & 4 & 5 & 6 & 7 & 8 & 9 & 10\end{array}$

33. Unwind

$\begin{array}{lllllllllllllllllllll}-10 & -9 & -8 & -7 & -6 & -5 & -4 & -3 & -2 & -1 & 0 & 1 & 2 & 3 & 4 & 5 & 6 & 7 & 8 & 9 & 10\end{array}$

34. Usual

$\begin{array}{lllllllllllllllllllll}-10 & -9 & -8 & -7 & -6 & -5 & -4 & -3 & -2 & -1 & 0 & 1 & 2 & 3 & 4 & 5 & 6 & 7 & 8 & 9 & 10\end{array}$

35. Lonely

$\begin{array}{lllllllllllllllllllll}-10 & -9 & -8 & -7 & -6 & -5 & -4 & -3 & -2 & -1 & 0 & 1 & 2 & 3 & 4 & 5 & 6 & 7 & 8 & 9 & 10\end{array}$

36. Serene

$\begin{array}{lllllllllllllllllllll}-10 & -9 & -8 & -7 & -6 & -5 & -4 & -3 & -2 & -1 & 0 & 1 & 2 & 3 & 4 & 5 & 6 & 7 & 8 & 9 & 10\end{array}$

37. Down

$\begin{array}{lllllllllllllllllllll}-10 & -9 & -8 & -7 & -6 & -5 & -4 & -3 & -2 & -1 & 0 & 1 & 2 & 3 & 4 & 5 & 6 & 7 & 8 & 9 & 10\end{array}$

38. Sociable

$\begin{array}{lllllllllllllllllllll}-10 & -9 & -8 & -7 & -6 & -5 & -4 & -3 & -2 & -1 & 0 & 1 & 2 & 3 & 4 & 5 & 6 & 7 & 8 & 9 & 10\end{array}$

39. Funny

$\begin{array}{lllllllllllllllllllll}-10 & -9 & -8 & -7 & -6 & -5 & -4 & -3 & -2 & -1 & 0 & 1 & 2 & 3 & 4 & 5 & 6 & 7 & 8 & 9 & 10\end{array}$

40. Brave

$\begin{array}{lllllllllllllllllllll}-10 & -9 & -8 & -7 & -6 & -5 & -4 & -3 & -2 & -1 & 0 & 1 & 2 & 3 & 4 & 5 & 6 & 7 & 8 & 9 & 10\end{array}$

41. Plain

$\begin{array}{lllllllllllllllllllll}-10 & -9 & -8 & -7 & -6 & -5 & -4 & -3 & -2 & -1 & 0 & 1 & 2 & 3 & 4 & 5 & 6 & 7 & 8 & 9 & 10\end{array}$ 


\begin{tabular}{|c|c|c|c|c|c|c|c|c|c|c|c|c|c|c|c|c|c|c|c|c|}
\hline \multicolumn{21}{|c|}{ 42. Sedated } \\
\hline-10 & -9 & -8 & -7 & -6 & -5 & -4 & -3 & -2 & -1 & 0 & 1 & 2 & 3 & 4 & 5 & 6 & 7 & 8 & 9 & 10 \\
\hline \multicolumn{21}{|l|}{ 43. Quiet } \\
\hline-10 & -9 & -8 & -7 & -6 & -5 & -4 & -3 & -2 & -1 & 0 & 1 & 2 & 3 & 4 & 5 & 6 & 7 & 8 & 9 & 10 \\
\hline \multicolumn{21}{|c|}{ 44. Courageous } \\
\hline-10 & -9 & -8 & -7 & -6 & -5 & -4 & -3 & -2 & -1 & 0 & 1 & 2 & 3 & 4 & 5 & 6 & 7 & 8 & 9 & 10 \\
\hline
\end{tabular}


Please rate your SEDATING OR AROUSING associations with each of the following words by circling the number that corresponds to your feelings. If you are unsure of the meaning of a word, please place a question mark next to it and move on to the next word.

Strongly

Sedating

Neutral

Strongly

Arousing

1. Talkative

$\begin{array}{lllllllllllllllllllll}-10 & -9 & -8 & -7 & -6 & -5 & -4 & -3 & -2 & -1 & 0 & 1 & 2 & 3 & 4 & 5 & 6 & 7 & 8 & 9 & 10\end{array}$

2. Comfortable

$\begin{array}{lllllllllllllllllllll}-10 & -9 & -8 & -7 & -6 & -5 & -4 & -3 & -2 & -1 & 0 & 1 & 2 & 3 & 4 & 5 & 6 & 7 & 8 & 9 & 10\end{array}$

3. Withdrawn

$\begin{array}{lllllllllllllllllllll}-10 & -9 & -8 & -7 & -6 & -5 & -4 & -3 & -2 & -1 & 0 & 1 & 2 & 3 & 4 & 5 & 6 & 7 & 8 & 9 & 10\end{array}$

4. Average

$\begin{array}{lllllllllllllllllllll}-10 & -9 & -8 & -7 & -6 & -5 & -4 & -3 & -2 & -1 & 0 & 1 & 2 & 3 & 4 & 5 & 6 & 7 & 8 & 9 & 10\end{array}$

5. Relaxed

$\begin{array}{lllllllllllllllllllll}-10 & -9 & -8 & -7 & -6 & -5 & -4 & -3 & -2 & -1 & 0 & 1 & 2 & 3 & 4 & 5 & 6 & 7 & 8 & 9 & 10\end{array}$

6. Neutral

$\begin{array}{lllllllllllllllllllll}-10 & -9 & -8 & -7 & -6 & -5 & -4 & -3 & -2 & -1 & 0 & 1 & 2 & 3 & 4 & 5 & 6 & 7 & 8 & 9 & 10\end{array}$

7. Happy

$\begin{array}{lllllllllllllllllllll}-10 & -9 & -8 & -7 & -6 & -5 & -4 & -3 & -2 & -1 & 0 & 1 & 2 & 3 & 4 & 5 & 6 & 7 & 8 & 9 & 10\end{array}$

8. Miserable

$\begin{array}{lllllllllllllllllllll}-10 & -9 & -8 & -7 & -6 & -5 & -4 & -3 & -2 & -1 & 0 & 1 & 2 & 3 & 4 & 5 & 6 & 7 & 8 & 9 & 10\end{array}$

9. Sad

$\begin{array}{lllllllllllllllllllll}-10 & -9 & -8 & -7 & -6 & -5 & -4 & -3 & -2 & -1 & 0 & 1 & 2 & 3 & 4 & 5 & 6 & 7 & 8 & 9 & 10\end{array}$

10. Normal

$\begin{array}{lllllllllllllllllllll}-10 & -9 & -8 & -7 & -6 & -5 & -4 & -3 & -2 & -1 & 0 & 1 & 2 & 3 & 4 & 5 & 6 & 7 & 8 & 9 & 10\end{array}$

11. Calm

$\begin{array}{lllllllllllllllllllll}-10 & -9 & -8 & -7 & -6 & -5 & -4 & -3 & -2 & -1 & 0 & 1 & 2 & 3 & 4 & 5 & 6 & 7 & 8 & 9 & 10\end{array}$

12. General

$\begin{array}{lllllllllllllllllllll}-10 & -9 & -8 & -7 & -6 & -5 & -4 & -3 & -2 & -1 & 0 & 1 & 2 & 3 & 4 & 5 & 6 & 7 & 8 & 9 & 10\end{array}$ 
13. Excited

$$
\begin{array}{lllllllllllllllllllll}
-10 & -9 & -8 & -7 & -6 & -5 & -4 & -3 & -2 & -1 & 0 & 1 & 2 & 3 & 4 & 5 & 6 & 7 & 8 & 9 & 10
\end{array}
$$

14. Peaceful

$$
\begin{array}{lllllllllllllllllllll}
-10 & -9 & -8 & -7 & -6 & -5 & -4 & -3 & -2 & -1 & 0 & 1 & 2 & 3 & 4 & 5 & 6 & 7 & 8 & 9 & 10
\end{array}
$$

15. Sluggish

$$
\begin{array}{lllllllllllllllllllll}
-10 & -9 & -8 & -7 & -6 & -5 & -4 & -3 & -2 & -1 & 0 & 1 & 2 & 3 & 4 & 5 & 6 & 7 & 8 & 9 & 10
\end{array}
$$

16. Energized

$$
\begin{array}{lllllllllllllllllllll}
-10 & -9 & -8 & -7 & -6 & -5 & -4 & -3 & -2 & -1 & 0 & 1 & 2 & 3 & 4 & 5 & 6 & 7 & 8 & 9 & 10
\end{array}
$$

17. Escape

$$
\begin{array}{lllllllllllllllllllll}
-10 & -9 & -8 & -7 & -6 & -5 & -4 & -3 & -2 & -1 & 0 & 1 & 2 & 3 & 4 & 5 & 6 & 7 & 8 & 9 & 10
\end{array}
$$

18. Regular

$$
\begin{array}{lllllllllllllllllllll}
-10 & -9 & -8 & -7 & -6 & -5 & -4 & -3 & -2 & -1 & 0 & 1 & 2 & 3 & 4 & 5 & 6 & 7 & 8 & 9 & 10
\end{array}
$$

19. Tired

$$
\begin{array}{lllllllllllllllllllll}
-10 & -9 & -8 & -7 & -6 & -5 & -4 & -3 & -2 & -1 & 0 & 1 & 2 & 3 & 4 & 5 & 6 & 7 & 8 & 9 & 10
\end{array}
$$

\section{Ordinary}

$$
\begin{array}{lllllllllllllllllllll}
-10 & -9 & -8 & -7 & -6 & -5 & -4 & -3 & -2 & -1 & 0 & 1 & 2 & 3 & 4 & 5 & 6 & 7 & 8 & 9 & 10
\end{array}
$$

\section{Depressed}

$$
\begin{array}{lllllllllllllllllllll}
-10 & -9 & -8 & -7 & -6 & -5 & -4 & -3 & -2 & -1 & 0 & 1 & 2 & 3 & 4 & 5 & 6 & 7 & 8 & 9 & 10
\end{array}
$$

22. Soothed

$$
\begin{array}{lllllllllllllllllllll}
-10 & -9 & -8 & -7 & -6 & -5 & -4 & -3 & -2 & -1 & 0 & 1 & 2 & 3 & 4 & 5 & 6 & 7 & 8 & 9 & 10
\end{array}
$$

23. Cheerful

$$
\begin{array}{lllllllllllllllllllll}
-10 & -9 & -8 & -7 & -6 & -5 & -4 & -3 & -2 & -1 & 0 & 1 & 2 & 3 & 4 & 5 & 6 & 7 & 8 & 9 & 10
\end{array}
$$

24. Typical

$$
\begin{array}{lllllllllllllllllllll}
-10 & -9 & -8 & -7 & -6 & -5 & -4 & -3 & -2 & -1 & 0 & 1 & 2 & 3 & 4 & 5 & 6 & 7 & 8 & 9 & 10
\end{array}
$$

25. Tranquil

$$
\begin{array}{lllllllllllllllllllll}
-10 & -9 & -8 & -7 & -6 & -5 & -4 & -3 & -2 & -1 & 0 & 1 & 2 & 3 & 4 & 5 & 6 & 7 & 8 & 9 & 10
\end{array}
$$

26. Confident

$$
\begin{array}{lllllllllllllllllllll}
-10 & -9 & -8 & -7 & -6 & -5 & -4 & -3 & -2 & -1 & 0 & 1 & 2 & 3 & 4 & 5 & 6 & 7 & 8 & 9 & 10
\end{array}
$$

27. Sick

$$
\begin{array}{lllllllllllllllllllll}
-10 & -9 & -8 & -7 & -6 & -5 & -4 & -3 & -2 & -1 & 0 & 1 & 2 & 3 & 4 & 5 & 6 & 7 & 8 & 9 & 10
\end{array}
$$


28. Carefree

$\begin{array}{lllllllllllllllllllll}-10 & -9 & -8 & -7 & -6 & -5 & -4 & -3 & -2 & -1 & 0 & 1 & 2 & 3 & 4 & 5 & 6 & 7 & 8 & 9 & 10\end{array}$

29. Basic

$\begin{array}{lllllllllllllllllllll}-10 & -9 & -8 & -7 & -6 & -5 & -4 & -3 & -2 & -1 & 0 & 1 & 2 & 3 & 4 & 5 & 6 & 7 & 8 & 9 & 10\end{array}$

30. Attractive

$\begin{array}{lllllllllllllllllllll}-10 & -9 & -8 & -7 & -6 & -5 & -4 & -3 & -2 & -1 & 0 & 1 & 2 & 3 & 4 & 5 & 6 & 7 & 8 & 9 & 10\end{array}$

31. Common

$\begin{array}{lllllllllllllllllllll}-10 & -9 & -8 & -7 & -6 & -5 & -4 & -3 & -2 & -1 & 0 & 1 & 2 & 3 & 4 & 5 & 6 & 7 & 8 & 9 & 10\end{array}$

32. Isolated

$\begin{array}{lllllllllllllllllllll}-10 & -9 & -8 & -7 & -6 & -5 & -4 & -3 & -2 & -1 & 0 & 1 & 2 & 3 & 4 & 5 & 6 & 7 & 8 & 9 & 10\end{array}$

33. Unwind

$\begin{array}{lllllllllllllllllllll}-10 & -9 & -8 & -7 & -6 & -5 & -4 & -3 & -2 & -1 & 0 & 1 & 2 & 3 & 4 & 5 & 6 & 7 & 8 & 9 & 10\end{array}$

34. Usual

$\begin{array}{lllllllllllllllllllll}-10 & -9 & -8 & -7 & -6 & -5 & -4 & -3 & -2 & -1 & 0 & 1 & 2 & 3 & 4 & 5 & 6 & 7 & 8 & 9 & 10\end{array}$

35. Lonely

$\begin{array}{lllllllllllllllllllll}-10 & -9 & -8 & -7 & -6 & -5 & -4 & -3 & -2 & -1 & 0 & 1 & 2 & 3 & 4 & 5 & 6 & 7 & 8 & 9 & 10\end{array}$

36. Serene

$\begin{array}{lllllllllllllllllllll}-10 & -9 & -8 & -7 & -6 & -5 & -4 & -3 & -2 & -1 & 0 & 1 & 2 & 3 & 4 & 5 & 6 & 7 & 8 & 9 & 10\end{array}$

37. Down

$\begin{array}{lllllllllllllllllllll}-10 & -9 & -8 & -7 & -6 & -5 & -4 & -3 & -2 & -1 & 0 & 1 & 2 & 3 & 4 & 5 & 6 & 7 & 8 & 9 & 10\end{array}$

38. Sociable

$\begin{array}{lllllllllllllllllllll}-10 & -9 & -8 & -7 & -6 & -5 & -4 & -3 & -2 & -1 & 0 & 1 & 2 & 3 & 4 & 5 & 6 & 7 & 8 & 9 & 10\end{array}$

39. Funny

$\begin{array}{lllllllllllllllllllll}-10 & -9 & -8 & -7 & -6 & -5 & -4 & -3 & -2 & -1 & 0 & 1 & 2 & 3 & 4 & 5 & 6 & 7 & 8 & 9 & 10\end{array}$

40. Brave

$\begin{array}{lllllllllllllllllllll}-10 & -9 & -8 & -7 & -6 & -5 & -4 & -3 & -2 & -1 & 0 & 1 & 2 & 3 & 4 & 5 & 6 & 7 & 8 & 9 & 10\end{array}$

41. Plain

$\begin{array}{lllllllllllllllllllll}-10 & -9 & -8 & -7 & -6 & -5 & -4 & -3 & -2 & -1 & 0 & 1 & 2 & 3 & 4 & 5 & 6 & 7 & 8 & 9 & 10\end{array}$

42. Sedated

$\begin{array}{lllllllllllllllllllll}-10 & -9 & -8 & -7 & -6 & -5 & -4 & -3 & -2 & -1 & 0 & 1 & 2 & 3 & 4 & 5 & 6 & 7 & 8 & 9 & 10\end{array}$ 


\begin{tabular}{|c|c|c|c|c|c|c|c|c|c|c|c|c|c|c|c|c|c|c|c|c|}
\hline \multirow{2}{*}{$\begin{array}{c}\text { 43. Quiet } \\
-10\end{array}$} & \multirow[b]{2}{*}{-9} & \multirow[b]{2}{*}{-8} & \multirow[b]{2}{*}{-7} & \multirow[b]{2}{*}{-6} & \multirow[b]{2}{*}{-5} & \multirow[b]{2}{*}{-4} & \multirow[b]{2}{*}{-3} & \multirow[b]{2}{*}{-2} & \multirow[b]{2}{*}{-1} & \multirow[b]{2}{*}{0} & \multirow[b]{2}{*}{1} & \multirow[b]{2}{*}{2} & \multirow[b]{2}{*}{3} & \multirow[b]{2}{*}{4} & \multirow[b]{2}{*}{5} & \multirow[b]{2}{*}{6} & \multirow[b]{2}{*}{7} & \multirow[b]{2}{*}{8} & \multirow[b]{2}{*}{9} & \multirow[b]{2}{*}{10} \\
\hline & & & & & & & & & & & & & & & & & & & & \\
\hline \multicolumn{3}{|c|}{ 44. Courageous } & & & & & & & & & & & & & & & & & & \\
\hline-10 & -9 & -8 & -7 & -6 & -5 & -4 & -3 & -2 & -1 & 0 & 1 & 2 & 3 & 4 & 5 & 6 & 7 & 8 & 9 & 10 \\
\hline
\end{tabular}


Please rate how much you think the following words are RELATED TO ALCOHOL by circling the appropriate number. If you are unsure of the meaning of a word, please place a question mark next to it and move on to the next word.

Strongly

Unrelated

Neutral

Strongly

Related

1. Talkative

$\begin{array}{lllllllllllllllllllll}-10 & -9 & -8 & -7 & -6 & -5 & -4 & -3 & -2 & -1 & 0 & 1 & 2 & 3 & 4 & 5 & 6 & 7 & 8 & 9 & 10\end{array}$

2. Comfortable

$\begin{array}{lllllllllllllllllllll}-10 & -9 & -8 & -7 & -6 & -5 & -4 & -3 & -2 & -1 & 0 & 1 & 2 & 3 & 4 & 5 & 6 & 7 & 8 & 9 & 10\end{array}$

3. Withdrawn

$\begin{array}{lllllllllllllllllllll}-10 & -9 & -8 & -7 & -6 & -5 & -4 & -3 & -2 & -1 & 0 & 1 & 2 & 3 & 4 & 5 & 6 & 7 & 8 & 9 & 10\end{array}$

4. Average

$\begin{array}{lllllllllllllllllllll}-10 & -9 & -8 & -7 & -6 & -5 & -4 & -3 & -2 & -1 & 0 & 1 & 2 & 3 & 4 & 5 & 6 & 7 & 8 & 9 & 10\end{array}$

5. Relaxed

$\begin{array}{lllllllllllllllllllll}-10 & -9 & -8 & -7 & -6 & -5 & -4 & -3 & -2 & -1 & 0 & 1 & 2 & 3 & 4 & 5 & 6 & 7 & 8 & 9 & 10\end{array}$

6. Neutral

$\begin{array}{lllllllllllllllllllll}-10 & -9 & -8 & -7 & -6 & -5 & -4 & -3 & -2 & -1 & 0 & 1 & 2 & 3 & 4 & 5 & 6 & 7 & 8 & 9 & 10\end{array}$

7. Happy

$\begin{array}{lllllllllllllllllllll}-10 & -9 & -8 & -7 & -6 & -5 & -4 & -3 & -2 & -1 & 0 & 1 & 2 & 3 & 4 & 5 & 6 & 7 & 8 & 9 & 10\end{array}$

8. Miserable

$\begin{array}{lllllllllllllllllllll}-10 & -9 & -8 & -7 & -6 & -5 & -4 & -3 & -2 & -1 & 0 & 1 & 2 & 3 & 4 & 5 & 6 & 7 & 8 & 9 & 10\end{array}$

9. Sad

$\begin{array}{lllllllllllllllllllll}-10 & -9 & -8 & -7 & -6 & -5 & -4 & -3 & -2 & -1 & 0 & 1 & 2 & 3 & 4 & 5 & 6 & 7 & 8 & 9 & 10\end{array}$

10. Normal

$\begin{array}{lllllllllllllllllllll}-10 & -9 & -8 & -7 & -6 & -5 & -4 & -3 & -2 & -1 & 0 & 1 & 2 & 3 & 4 & 5 & 6 & 7 & 8 & 9 & 10\end{array}$

11. Calm

$\begin{array}{lllllllllllllllllllll}-10 & -9 & -8 & -7 & -6 & -5 & -4 & -3 & -2 & -1 & 0 & 1 & 2 & 3 & 4 & 5 & 6 & 7 & 8 & 9 & 10\end{array}$

12. General

$\begin{array}{lllllllllllllllllllll}-10 & -9 & -8 & -7 & -6 & -5 & -4 & -3 & -2 & -1 & 0 & 1 & 2 & 3 & 4 & 5 & 6 & 7 & 8 & 9 & 10\end{array}$

13. Excited

$\begin{array}{lllllllllllllllllllll}-10 & -9 & -8 & -7 & -6 & -5 & -4 & -3 & -2 & -1 & 0 & 1 & 2 & 3 & 4 & 5 & 6 & 7 & 8 & 9 & 10\end{array}$ 
14. Peaceful

$\begin{array}{lllllllllllllllllllll}-10 & -9 & -8 & -7 & -6 & -5 & -4 & -3 & -2 & -1 & 0 & 1 & 2 & 3 & 4 & 5 & 6 & 7 & 8 & 9 & 10\end{array}$

15. Sluggish

$\begin{array}{lllllllllllllllllllll}-10 & -9 & -8 & -7 & -6 & -5 & -4 & -3 & -2 & -1 & 0 & 1 & 2 & 3 & 4 & 5 & 6 & 7 & 8 & 9 & 10\end{array}$

16. Energized

$\begin{array}{lllllllllllllllllllll}-10 & -9 & -8 & -7 & -6 & -5 & -4 & -3 & -2 & -1 & 0 & 1 & 2 & 3 & 4 & 5 & 6 & 7 & 8 & 9 & 10\end{array}$

17. Escape

$\begin{array}{lllllllllllllllllllll}-10 & -9 & -8 & -7 & -6 & -5 & -4 & -3 & -2 & -1 & 0 & 1 & 2 & 3 & 4 & 5 & 6 & 7 & 8 & 9 & 10\end{array}$

18. Regular

$\begin{array}{lllllllllllllllllllll}-10 & -9 & -8 & -7 & -6 & -5 & -4 & -3 & -2 & -1 & 0 & 1 & 2 & 3 & 4 & 5 & 6 & 7 & 8 & 9 & 10\end{array}$

19. Tired

$\begin{array}{lllllllllllllllllllll}-10 & -9 & -8 & -7 & -6 & -5 & -4 & -3 & -2 & -1 & 0 & 1 & 2 & 3 & 4 & 5 & 6 & 7 & 8 & 9 & 10\end{array}$

20. Ordinary

$\begin{array}{lllllllllllllllllllll}-10 & -9 & -8 & -7 & -6 & -5 & -4 & -3 & -2 & -1 & 0 & 1 & 2 & 3 & 4 & 5 & 6 & 7 & 8 & 9 & 10\end{array}$

21. Depressed

$\begin{array}{lllllllllllllllllllll}-10 & -9 & -8 & -7 & -6 & -5 & -4 & -3 & -2 & -1 & 0 & 1 & 2 & 3 & 4 & 5 & 6 & 7 & 8 & 9 & 10\end{array}$

22. Soothed

$\begin{array}{lllllllllllllllllllll}-10 & -9 & -8 & -7 & -6 & -5 & -4 & -3 & -2 & -1 & 0 & 1 & 2 & 3 & 4 & 5 & 6 & 7 & 8 & 9 & 10\end{array}$

23. Cheerful

$\begin{array}{lllllllllllllllllllll}-10 & -9 & -8 & -7 & -6 & -5 & -4 & -3 & -2 & -1 & 0 & 1 & 2 & 3 & 4 & 5 & 6 & 7 & 8 & 9 & 10\end{array}$

24. Typical

$\begin{array}{lllllllllllllllllllll}-10 & -9 & -8 & -7 & -6 & -5 & -4 & -3 & -2 & -1 & 0 & 1 & 2 & 3 & 4 & 5 & 6 & 7 & 8 & 9 & 10\end{array}$

25. Tranquil

$\begin{array}{lllllllllllllllllllll}-10 & -9 & -8 & -7 & -6 & -5 & -4 & -3 & -2 & -1 & 0 & 1 & 2 & 3 & 4 & 5 & 6 & 7 & 8 & 9 & 10\end{array}$

26. Confident

$\begin{array}{lllllllllllllllllllll}-10 & -9 & -8 & -7 & -6 & -5 & -4 & -3 & -2 & -1 & 0 & 1 & 2 & 3 & 4 & 5 & 6 & 7 & 8 & 9 & 10\end{array}$

27. Sick

$\begin{array}{lllllllllllllllllllll}-10 & -9 & -8 & -7 & -6 & -5 & -4 & -3 & -2 & -1 & 0 & 1 & 2 & 3 & 4 & 5 & 6 & 7 & 8 & 9 & 10\end{array}$

28. Carefree

$\begin{array}{lllllllllllllllllllll}-10 & -9 & -8 & -7 & -6 & -5 & -4 & -3 & -2 & -1 & 0 & 1 & 2 & 3 & 4 & 5 & 6 & 7 & 8 & 9 & 10\end{array}$ 
29. Basic

$\begin{array}{lllllllllllllllllllll}-10 & -9 & -8 & -7 & -6 & -5 & -4 & -3 & -2 & -1 & 0 & 1 & 2 & 3 & 4 & 5 & 6 & 7 & 8 & 9 & 10\end{array}$

30. Attractive

$\begin{array}{lllllllllllllllllllll}-10 & -9 & -8 & -7 & -6 & -5 & -4 & -3 & -2 & -1 & 0 & 1 & 2 & 3 & 4 & 5 & 6 & 7 & 8 & 9 & 10\end{array}$

31. Common

$\begin{array}{lllllllllllllllllllll}-10 & -9 & -8 & -7 & -6 & -5 & -4 & -3 & -2 & -1 & 0 & 1 & 2 & 3 & 4 & 5 & 6 & 7 & 8 & 9 & 10\end{array}$

32. Isolated

$\begin{array}{lllllllllllllllllllll}-10 & -9 & -8 & -7 & -6 & -5 & -4 & -3 & -2 & -1 & 0 & 1 & 2 & 3 & 4 & 5 & 6 & 7 & 8 & 9 & 10\end{array}$

33. Unwind

$\begin{array}{lllllllllllllllllllll}-10 & -9 & -8 & -7 & -6 & -5 & -4 & -3 & -2 & -1 & 0 & 1 & 2 & 3 & 4 & 5 & 6 & 7 & 8 & 9 & 10\end{array}$

34. Usual

$\begin{array}{lllllllllllllllllllll}-10 & -9 & -8 & -7 & -6 & -5 & -4 & -3 & -2 & -1 & 0 & 1 & 2 & 3 & 4 & 5 & 6 & 7 & 8 & 9 & 10\end{array}$

35. Lonely

$\begin{array}{lllllllllllllllllllll}-10 & -9 & -8 & -7 & -6 & -5 & -4 & -3 & -2 & -1 & 0 & 1 & 2 & 3 & 4 & 5 & 6 & 7 & 8 & 9 & 10\end{array}$

36. Serene

$\begin{array}{lllllllllllllllllllll}-10 & -9 & -8 & -7 & -6 & -5 & -4 & -3 & -2 & -1 & 0 & 1 & 2 & 3 & 4 & 5 & 6 & 7 & 8 & 9 & 10\end{array}$

37. Down

$\begin{array}{lllllllllllllllllllll}-10 & -9 & -8 & -7 & -6 & -5 & -4 & -3 & -2 & -1 & 0 & 1 & 2 & 3 & 4 & 5 & 6 & 7 & 8 & 9 & 10\end{array}$

38. Sociable

$\begin{array}{lllllllllllllllllllll}-10 & -9 & -8 & -7 & -6 & -5 & -4 & -3 & -2 & -1 & 0 & 1 & 2 & 3 & 4 & 5 & 6 & 7 & 8 & 9 & 10\end{array}$

39. Funny

$\begin{array}{lllllllllllllllllllll}-10 & -9 & -8 & -7 & -6 & -5 & -4 & -3 & -2 & -1 & 0 & 1 & 2 & 3 & 4 & 5 & 6 & 7 & 8 & 9 & 10\end{array}$

40. Brave

$\begin{array}{lllllllllllllllllllll}-10 & -9 & -8 & -7 & -6 & -5 & -4 & -3 & -2 & -1 & 0 & 1 & 2 & 3 & 4 & 5 & 6 & 7 & 8 & 9 & 10\end{array}$

41. Plain

$\begin{array}{lllllllllllllllllllll}-10 & -9 & -8 & -7 & -6 & -5 & -4 & -3 & -2 & -1 & 0 & 1 & 2 & 3 & 4 & 5 & 6 & 7 & 8 & 9 & 10\end{array}$

42. Sedated

$\begin{array}{lllllllllllllllllllll}-10 & -9 & -8 & -7 & -6 & -5 & -4 & -3 & -2 & -1 & 0 & 1 & 2 & 3 & 4 & 5 & 6 & 7 & 8 & 9 & 10\end{array}$

43. Quiet

$\begin{array}{lllllllllllllllllllll}-10 & -9 & -8 & -7 & -6 & -5 & -4 & -3 & -2 & -1 & 0 & 1 & 2 & 3 & 4 & 5 & 6 & 7 & 8 & 9 & 10\end{array}$ 
44. Courageous

$$
\begin{array}{lllllllllllllllllllll}
-10 & -9 & -8 & -7 & -6 & -5 & -4 & -3 & -2 & -1 & 0 & 1 & 2 & 3 & 4 & 5 & 6 & 7 & 8 & 9 & 10
\end{array}
$$


Below are some words that refer to alcoholic drinks:
Beer
Wine
Liquor
Vodka
Rum
Whiskey

Please list additional words that you can think of that refer to alcoholic drinks:

Below are some words that refer to non-alcoholic drinks:
Soda
Water
Juice
Milk
Sprite
Coke

Please list additional words that you can think of that refer to non-alcoholic drinks:

Thanks again for your help! Please share any comments or concerns here: 


\section{BIBLIOGRAPHY}

Aiken, L.S., \& West, S.G. (1991). Interactions between continuous predictors in multiple regression. In Multiple regression: Testing and interpreting interactions (pp. 9-27). Newbury Park: Sage Publications.

Baker, L., Prevatt, F., \& Proctor, B. (2012). Drug and alcohol use in college students with and without ADHD. Journal of Attention Disorder, 16(3), 255-263.

Banaji, M.R. \& Heiphetz, L. (2010). Attitudes. In S.T. Fiske, D.T. Gilbert, \& G. Lindzey (Eds.), Handbook of Social Psychology (5 ${ }^{\text {th }}$ ed., Vol. 1, pp. 353-393). New Jersey: John Wiley \& Sons, Inc.

Brehmer, Y., Westerberg, H., \& Backman, L. (2012). Working-memory training in younger and older adults: training gains, transfer, and maintenance. Frontiers in human neuroscience, 6, 1-7.

Crews, F.T., \& Boettiger, C.A. (2009). Impulsivity, frontal lobes and risk for addiction. Pharmacology, Biochemistry and Behavior, 93, 237-247.

Dick, D.M., Smith, G., Olausson, P., Mitchell, S.H., Leeman, R.F., O’Malley, S.S., \& Sher, K. (2010). Understanding the construct of impulsivity and its relationship to alcohol use disorders. Addiction Biology, 15, 217-226.

Dougherty, D.M., Mathia, C.W., Marsh, D.M., \& Jagar, A.A. (2005). Laboratory behavioral measures of impulsivity. Behavior Research Methods, 37, 82-90.

Engle, R.W. (2002). Working memory capacity as executive attention. Current Directions in Psychological Science, 11, 19-23.

Fromme, K., Stroot, E., \& Kaplan, D. (1993). Comprehensive effects of alcohol: Development and psychometric assessment of a new expectancy questionnaire. Psychological Assessment, 5, 19-26.

Giancola, P.R. \& Tarter, R.E. (1999). Executive cognitive functioning and risk for substance abuse. Psychological Science, 10, 203-205.

Golden, C.J. (1978). Stroop Color and Word Test: A manual for clinical and experimental uses. Chicago, IL: Skoelting.

Goldman, M.S., Del Boca, F.K., \& Darkes, J. (1999). Alcohol expectancy theory: The application of cognitive neuroscience. In K.E. Leonard \& H.T. Blane (Eds.), Psychological theories of drinking and alcoholism (2 ${ }^{\text {nd }}$ ed., pp. 203-246). New York: Guildford Press. 
Greenwald, A.G., McGhee, D.E., \& Schwartz, L.K. (1998). Measuring individual differences in implicit cognition: The Implicit Association Test. Journal of Personality and Social Psychology, 74, 1464-1480.

Greenwald, A.G., Poehlman, T.A., Uhlmann, E.L., \& Banaji, M.R. (2009). Understanding and using the Implicit Association Test: III. Meta-analysis of predictive validity. Journal of Personality and Social Psychology, 97, 17-41.

Grenard, J.L., Ames, S.L., Wiers, R.W., Thush, C., Sussman, S., \& Stacy, A.W. (2008). Working memory capacity moderates the predictive effects of drugrelated associations on substance use. Psychology of Addictive Behaviors, 22, 426-432.

Gropper, R.J., \& Tannock, R. (2009). A pilot study of working memory and academic achievement in college students with ADHD. Journal of Attention Disorders, 12, 574-581.

Hatcher, L. (1994). A step-by-step approach to using SAS for factor analysis and structural equation modeling. Cary, NC: SAS Institute Inc.

Harlow, L.L. (2005). The essence of multivariate thinking: Basic themes and methods. Mahwah: Lawrence Erlbaum Associates.

Hingson, R.W., Zha, W., \& Weitzman, E.R. (2009). Magnitude of and trends in alcohol-related mortality and morbidity among U.S. college students ages 1824, 1998-2005. Journal of Studies on Alcohol and Drugs, Suppl. 16, 12-20.

Hofmann, W., Friese, M., \& Wiers, R.W. (2009). Impulsive versus reflective influences on health behavior: a theoretical framework and empirical review. Health Psychology Review, 2, 1-27.

Hofmann, W., Gschwendner, T., Friese, M., Wiers, R.W., \& Schmitt, M. (2008). Working memory capacity and self-regulatory behavior: Toward an individual differences perspective on behavior determination by automatic versus controlled processes. Journal of Personality and Social Psychology, 95, 962977.

Homack, S., \& Riccio, C.A. (2004). A meta-analysis of the sensitivity and specificity of the Stroop Color and Word Test with children. Archives of Clinical Neuropsychology, 19, 725-743.

Houben, K., Havermans, R.C., Nederkoorn, C., \& Jansen, A. (2012). Been a no-go: learning to stop responding to alcohol cues reduces alcohol intake via reduced affective associations rather than increased response inhibition. Addiction, 107, 1280-1287. 
Houben, K., Havermans, R.C., \& Wiers, R.W. (2010). Learning to dislike alcohol: conditioning negative implicit attitudes toward alcohol and its effect on drinking behavior. Psychopharmacology, 211, 79-86.

Houben, K., Nederkoorn, C., Wiers, R.W., \& Jansen, A. (2011). Resisting temptation: Decreasing alcohol-related affect and drinking behavior by training response inhibition. Drug and Alcohol Dependence, 116, 132-136.

Houben, K., Nosek, B.A., \& Wiers, R.W. (2010). Seeing the forest through the trees: a comparison of different IAT variants measuring implicit alcohol associations. Drug and Alcohol Dependence, 106, 204-211.

Houben, K., \& Wiers, R.W. (2006). Assessing implicit alcohol associations with the Implicit Association Test: Fact or artifact? Addictive Behaviors, 31, 13461362.

Houben, K., \& Wiers, R.W. (2009). Response inhibition moderates the relationship between implicit associations and drinking behavior. Alcoholism: Clinical and Experimental Research, 33, 626-633.

Jajodia, A., \& Earleywine M. (2003). Measuring alcohol expectancies with the implicit association test. Psychology of Addictive Behaviors, 17, 126-133.

Jones, A., \& Field, M. (2012). The effects of cue-specific inhibition training on alcohol consumption in heavy social drinkers. Experimental and Clinical Psychopharmacology. Advance online publication. doi: 10.1037/a0030683.

Kahler, C.W., Strong, D.R., \& Read, J.P. (2005). Toward efficient and comprehensive measurement of the alcohol problems continuum in college students: The Brief Young Adult Alcohol Consequences Questionnaire. Alcoholism: Clinical and Experimental Research, 29, 1180-1189.

Kline, R.B. (2005). Principles and practice of structural equation modeling ( ${ }^{\text {nd }}$ ed.). New York: Guilford Press.

Klingberg (2010). Training and plasticity of working memory. Trends in Cognitive Sciences, 14, 317-324.

Kushner,M. G., Sher, K. J.,Wood, M. D., \&Wood, P. K. (1994). Anxiety and drinking behavior: Moderating effects of tension-reduction alcohol outcome expectancies. Alcoholism: Clinical and Experimental Research, 18, 852-860.

Labbe, A.K. \& Maisto, S.A. (2011). Alcohol expectancy challenges for college students: A narrative review. Clinical Psychology Review, 31, 673-683. 
Lawrence, A.J., Luty, J., Bogdan, N.A., Sahakian, B.J., \& Clark, L. (2009). Impulsivity and response inhibition in alcohol dependence and problem gambling. Psychopharmacology, 207, 163-172.

Leigh, B.C. (1989). In search of the seven dwarves: issues of measurement and meaning in alcohol expectancy research. Psychological Bulletin, 105, 361-373.

Leigh, B.C., \& Stacy, A.W. (1993). Alcohol outcome expectancies: scale construction and predictive utility in higher order confirmatory models. Psychological Assessment, 5, 216-229.

Leigh, B.C., \& Stacy, A.W. (1998). Individual differences in memory associations involving the positive and negative outcomes of alcohol use. Psychology of Addictive Behaviors, 12, 39-46.

Lindgren, K.P., Neighbors, C., Teachman, B.A., Wiers, R.W., Westgate, E., \& Greenwald, A.G. (2012). I drink therefore I am: Validating alcohol-related Implicit Association Tasks. Psychology of Addictive Behaviors. Advance online publication. doi: 10.1037/a0027640

Martin, C.S., Earleywine, M., Musty, R.E., Perrine, M.W., \& Swift, R.M. (1993). Development and validation of the biphasic alcohol effects scale. Alcoholism: Clinical and Experimental Research, 17, 140-146.

McClelland, G.H., \& Judd, C.M. (1993). Statistical difficulties of detecting interactions and moderator effects. Psychological Bulletin, 114, 376-390.

Palfai, T. \& Wood, M.D. (2001). Positive alcohol expectancies and drinking behavior: The influence of expectancy strength and memory accessibility. Psychology of Addictive Behaviors, 15, 60-67.

Patrick, M.E., Wray-Lake, L., Finlay, A.K., \& Maggs, J.L. (2010). The long arm of expectancies: Adolescent alcohol expectancies predict adult alcohol use. Alcohol \& Alcoholism, 45, 17-24.

Peeters, M., Wiers, R.W., Monshouwer, K., van de Schoot, R., Janssen, T., \& Vollebergh, W.A.M. (2012). Automatic processes in at-risk adolescents: the role of alcohol-approach tendencies and response inhibition in drinking behavior. Addiction, 107, 1939-1946.

Perkins, H.W. (2002). Surveying the damage: A review of research on consequences of alcohol misuse in college populations. Journal of Studies on Alcohol, Suppl. 14, 91-100.

Petrides, M., \& Milner, B. (1982). Deficits on subject-ordered tasks after frontal- and temporal-lobe lesions in man. Neuropsychologia, 20, 249-262. 
Piechatzek, M., Indlekofer, F., Daamen, M., Glasmacher, C., Lieb, R., Pfister, H., Tucha, O., Lange, K.W., Wittchen, H.U., \& Schutz, C.G. (2009). Is moderate substance use associated with altered executive functioning in a populationbased sample of young adults? Human Psychopharmacology: Clinical and Experimental, 24, 650-665.

Pukrop, R., Matuschek, E., Ruhrmann, S., Brockhaus-Dumke, A., Tendolkar, I., Bertsch, A., \& Klosterkotter, J. (2003). Dimensions of working memory dysfunction in schizophrenia. Schizophrenia Research, 62, 259-268.

Rather, B.C., Goldman, M.S., Roehrich, L., \& Brannick, M. (1992). Empirical modeling of an alcohol expectancy memory network using multidimensional scaling. Journal of Abnormal Psychology, 101, 174-183.

Read, J.P., Merrill, J.E., Kahler, C.W., \& Strong, D.R. (2007). Predicting functional outcomes among college drinkers: reliability and predictive validity of the Young Adult Alcohol Consequences Questionnaire. Addictive Behaviors, 32, 2597-2610.

Reynolds, B., Ortengren, A., Richards, J.B., de Wit, H. (2006). Dimensions of impulsive behavior: Personality and behavior measures. Personality and Individual Differences, 40, 305-315.

Rooney, M., Chronis-Tuscano, A., \& Yoon, Y. (2012). Substance Use in College Students with ADHD. Journal of Attention Disorders, 16(3), 221-234.

Ross, T.P., Hanouskova, E., Giarla, K., Calhoun, E., \& Tucker, M. (2007). The reliability and validity of the self-ordered pointing task. Archives of Clinical Neuropsychology, 22, 449-458.

Schnabel, K., Asendorpf, J.B., \& Greenwald, A.G. (2008). Assessment of individual differences in implicit cognition: A review of IAT measures. European Journal of Psychological Assessment, 24, 210-217.

Sher, K.J., Wood, M.D., Wood, P.K., \& Raskin, G. (1996). Alcohol outcome expectancies and alcohol use: A latent variable cross-lagged panel study. Journal of Abnormal Psychology, 105, 561-574.

Shiffrin, R.M., \& Schneider, W. (1977). Controlled and automatic human information processing: II. Perceptual learning, automatic attending, and a general theory. Psychological Review, 84, 127-190.

Smith, G.T., Goldman, M.S., \& Greenbaum, P.E., (1995). Expectancy for social facilitation from drinking: The divergent paths of high-expectancy and lowexpectancy adolescents. Journal of Abnormal Psychology, 104, 32-40. 
Sobell, L.C., \& Sobell, M.B. (1995). Alcohol consumption measures. In J. P. Allen \& M. Columbus (Eds.) Assessing alcohol problems: A guide for clinicians and researchers (pp. 55-73). Bethesda, MD: National Institute on Alcohol Abuse and Alcoholism.

Sobell, M.B., Sobell, L.C., Klajner, F., Pavan, D., \& Basian, E. (1986). The reliability of a timeline method for assessing normal drinker college students' recent drinking history: utility for alcohol research. Addictive Behaviors, 11, 149-161.

Stacy, A.W. (1997). Memory activation and expectancy as prospective predictors of alcohol and marijuana use. Journal of Abnormal Psychology, 106, 61-73.

Stacy, A.W., Ames, S.L., Sussman, S., \& Dent, C.W. (1996). Implicit cognition in adolescent drug use. Psychology of Addictive Behaviors, 10, 190-203.

Stacy, A.W. \& Wiers, R.W. (2010). Implicit cognition and addiction: A tool for explaining paradoxical behavior. Annual Review in Clinical Psychology, 6, 551-575.

Strack, F., \& Deutsch, R. (2004). Reflective and impulsive determinants of social behavior. Personality and Social Psychology Review, 8, 220-247.

Stroop, J.R. (1935). Studies of interference in serial verbal reactions. Journal of Experimental Psychology, 18, 643-662.

Tabachnick, B.G. \& Fidell, L.S. (2001). Using multivariate statistics $-4^{\text {th }}$ edition. Boston: Allyn and Bacon.

Thush, C. \& Wiers, R.W. (2007). Explicit and implicit alcohol-related cognitions and the prediction of future drinking in adolescents. Addictive Behaviors, 32, 13671383.

Thush, C., Wiers, R.W., Ames, S.L., Grenard, J.L., Sussman, S., \& Stacy, A.W. (2008). Interactions between implicit and explicit cognition and working memory capacity in the prediction of alcohol use in at-risk adolescents. Drug and Alcohol Dependence, 94, 116-124.

Wechsler, D. (2008). Wechsler Adult Intelligence Scale - Fourth Edition: Administration and Scoring Manual. San Antonio: Pearson.

Wechsler, H., Lee, J.E., Kuo, M., \& Lee, H. (2000). College binge drinking in the 1990s: A continuing problem. Results of the Harvard School of Public Health 1999 College Alcohol Study. Journal of American College Health, 48, 199210. 
Wiers, R.W., Bartholow, B.D., van den Wildenberg, E., Thush, C., Engels, R.C.M.E., Sher, K.J., Grenard, J., Ames, S.L., \& Stacy, A.W. (2007). Automatic and controlled processes and the development of addictive behaviors in adolescents: A review and a model. Pharmacology, Biochemistry and Behavior, 86, 263-283.

Wiers, R.W., Beckers, L., Houben, K., \& Hofmann, W. (2009). A short fuse after alcohol: Implicit power associations predict aggressiveness after alcohol consumption in young heavy drinkers with limited executive control. Pharmacology, Biochemistry, and Behavior, 93, 300-305.

Wiers, R.W., Eberl, C., Rinck, M., Becker, E.S., \& Lindenmeyer, J. (2011). Retraining automatic action tendencies changes alcohol patients' approach bias for alcohol and improves treatment outcome. Psychological Science, 22, 490-497.

Wiers, R.W., Rinck, M., Kordts, R., Houben, K., \& Strack, F. (2010). Retraining automatic action-tendencies to approach alcohol in hazardous drinkers. Addiction, 105, 279-287.

Wiers, R.W., \& Stacy, A.W. (2010). Are alcohol expectancies associations? Comment on Moss and Albery (2009). Psychological Bulletin, 136, 12-16.

Wiers, R.W., van Woerden, N., Smulders, F.T.Y., \& de Jong, P.J. (2002). Implicit and explicit alcohol-related cognitions in heavy and light drinkers. Journal of Abnormal Psychology, 111, 648-658.

Wiers, R.W., Houben, K., Roefs, A., de Jong, P., Hofmann, W., \& Stacy, A.W. (2010). Implicit cognition in health psychology: Why common sense goes out the window. In B. Gawronski \& B.K. Payne (Eds.), Handbook of implicit social cognition: Measurement, Theory, and Applications (pp. 463-488). New York: Guildford Press.

Wiers, R.W., Houben, K., Smulders, F.T.Y., Conrod, P.J., \& Jones, B.T. (2006). To drink or not to drink: The role of automatic and controlled cognitive processes in the etiology of alcohol-related problems. In R.W. Wiers \& A.W. Stacy (Eds.), Handbook of implicit cognition and addiction (pp. 11-28). Thousand Oaks: Sage Publications.

Wilens, T.E. (1998). AOD use and Attention Deficit/Hyperactivity Disorder. Alcohol Health \& Research World, 22, 127-130.

Wood, M.D., Capone, C., Laforge, R., Erickson, D.J., \& Brand, N.H. (2007). Brief motivational intervention and alcohol expectancy challenge with heavy drinking college students: A randomized factorial study. Addictive Behaviors, $32,2509-2528$. 